OPEN ACCESS

Edited by:

Irina Ivanova Stoyanova, Medical University of Varna, Bulgaria

Reviewed by:

Carola A. Haas,

University of Freiburg, Germany HsuehCheng Chiang, National Cheng Kung University,

Taiwan

*Correspondence:

Eckart Förster

eckart.foerster@rub.de

${ }^{\dagger}$ These authors have contributed equally to this work

Specialty section:

This article was submitted to

Signaling,

a section of the journal

Frontiers in Cell and Developmental

Biology

Received: 06 November 2020

Accepted: 03 February 2021

Published: 22 February 2021

Citation:

Weninger J, Meseke M, Rana S and Förster E (2021) Heat-Shock Induces Granule Cell Dispersion and Microgliosis in Hippocampal

Slice Cultures.

Front. Cell Dev. Biol. 9:626704. doi: 10.3389/fcell.2021.626704

\section{Heat-Shock Induces Granule Cell Dispersion and Microgliosis in Hippocampal Slice Cultures}

\author{
Jasmin Weningert, Maurice Meseke', Shaleen Rana and Eckart Förster* \\ Institute of Anatomy, Department of Neuroanatomy and Molecular Brain Research, Ruhr-Universität Bochum, Bochum, \\ Germany
}

Granule cell dispersion (GCD) has been found in the dentate gyrus (dg) of patients with temporal lobe epilepsy (TLE) and a history of febrile seizures but was also recently observed in pediatric patients that did not suffer from epilepsy. This indicates that GCD might not always be disease related, but instead could reflect normal morphological variation. Thus, distribution of newborn granule cells within the hilar region is part of normal dg development at early stages but could be misinterpreted as pathological GCD. In turn, pathological GCD may be caused, for example, by genetic mutations, such as the reeler mutation. GCD in the reeler mutant goes along with an increased susceptibility to epileptiform activity. Pathological GCD in combination with epilepsy is caused by experimental administration of the glutamate receptor agonist kainic acid in rodents. In consequence, the interpretation of GCD and the role of febrile seizures remain controversial. Here, we asked whether febrile temperatures alone might be sufficient to trigger GCD and used hippocampal slice cultures as in vitro model to analyze the effect of a transient temperature increase on the dg morphology. We found that a heat-shock of $41^{\circ} \mathrm{C}$ for $6 \mathrm{~h}$ was sufficient to induce GCD and degeneration of a fraction of granule cells. Both of these factors, broadening of the granule cell layer ( $\mathrm{gcl}$ ) and increased neuronal cell death within the gcl, contributed to the development of a significantly reduced packaging density of granule cells. In contrast, Reelin expressing Cajal-Retzius (CR) cells in the molecular layer were heat-shock resistant. Thus, their number was not reduced, and we did not detect degenerating CR cells after heat-shock, implying that GCD was not caused by the loss of CR cells. Importantly, the heat-shockinduced deterioration of dg morphology was accompanied by a massive microgliosis, reflecting a robust heat-shock-induced immune response. In contrast, in the study that reported on GCD as a non-specific finding in pediatric patients, no microglia reaction was observed. Thus, our findings underpin the importance of microglia as a marker to distinguish pathological GCD from normal morphological variation.

Keywords: epilepsy, Cajal-Retzius cells, Reelin, CNS inflammation, hippocampus, Prox-1 


\section{INTRODUCTION}

Epilepsy encompasses a variety of neurological pathologies, in particular recurrent seizures of hyperexcitable nerve cells and the associated imbalance between excitation and inhibition (Bozzi et al., 2012). Although knowledge on the various causes of these paroxysmal synchronous neuronal discharges in the brain has significantly increased in recent years, the underlying pathological mechanisms, including immunological responses to epileptic seizures, are far from being understood. Complex febrile seizures in early life are thought to be associated with the development of temporal lobe epilepsy (TLE), a disease with strong clinical relevance, and are also suspected to be causally linked to hippocampal lesions later in life (Rocca et al., 1987; Abou-Khalil et al., 1993; Cendes et al., 1993; French et al., 1993; Bender et al., 2004; Vezzani and Granata, 2005; Dube et al., 2009; Koyama, 2013). Juvenile complex febrile seizures were reported to induce dentate granule cell ectopia (Koyama et al., 2012), possibly caused by impaired Reelin signaling. Moreover, granule cell dispersion (GCD) is frequently observed in hippocampal tissue affected by TLE (Houser, 1990; Lurton et al., 1997; Haas et al., 2002; Gong et al., 2007; Blumcke et al., 2009; Haas and Frotscher, 2010), and previous studies have shown that granule cell displacement can lead to incorrect connections of these neurons, which may favor the development of epileptic discharges (Dashtipour et al., 2001; Kowalski et al., 2010; Cameron et al., 2011). In turn, GCD has also been observed in the dentate gyrus (dg) of pediatric patients that did not suffer from epilepsy, suggesting that GCD may be within the normal variation range of granule cell layer (gcl) morphology (Roy et al., 2020).

The extracellular matrix protein Reelin controls several aspects of cortical development and function, in particular the positioning of radially migrating neurons and layer formation, including formation of the dentate gcl (Frotscher, 1998; Rice and Curran, 2001; Tissir and Goffinet, 2003; Forster et al., 2006b; Folsom and Fatemi, 2013). In the reeler mutant mouse, which does not express Reelin, cortical neurons display characteristic migration defects. In the reeler hippocampus, dentate granule cells are not organized in a compact layer but dispersed throughout the hilar region, reminiscent of pathological GCD (D’Arcangelo et al., 1995; Forster et al., 2006b). Therefore, loss of the extracellular matrix protein Reelin, expressed and secreted by CR cells in the dentate molecular layer, is suspected to be a possible cause for the development of GCD in the epileptic hippocampus (Haas et al., 2002; Heinrich et al., 2006; Muller et al., 2009; Duveau et al., 2011).

An increasing number of different clinical and experimental studies point to a correlation between the pathophysiology of epilepsy and inflammation in the central nervous system, including the accumulation, proliferation, and activation of glial cells, in particular of microglia (Choi and Koh, 2008; Vezzani and Ruegg, 2011; Vezzani et al., 2011). Microglia activity promotes cellular immunity and restores physiological homeostasis in the brain by phagocytosis of cell debris and pathogens (Hanisch and Kettenmann, 2007; Devinsky et al., 2013). However, little is known about the interplay between cells of the immune system and neurons in the central nervous system during heat-shock and the subsequent degenerative and regenerative processes.

Organotypic slice cultures of the hippocampal region are a well-established in vitro model to study development, function, and plasticity of hippocampal neurons and glial cells in health and disease in a tissue context that is similar to the in vivo situation (Forster et al., 1993; Del Rio et al., 1996; Forster et al., 2006b; del Rio and Soriano, 2010; Koyama, 2013). To study the impact of a transient temperature increase on the $\mathrm{dg}$, the incubation temperature of hippocampal slice cultures was increased from 37 to $41^{\circ} \mathrm{C}$ for $6 \mathrm{~h}$. Subsequent to this heat-shock, we investigated its impact on the morphology of the dentate gcl, on the survival of granule cells and CR cells, and on the distribution and proliferation of microglial cells in the dg.

\section{MATERIALS AND METHODS}

\section{Animals}

Wistar rat pups (postnatal day 5) were used for hippocampal slice cultures. Animals were bred and maintained in accordance with the animal care guidelines of the institutional guidelines of the University of Bochum. All animals were housed at $22^{\circ} \mathrm{C}$ on a $12 \mathrm{~h} \mathrm{light/dark}$ cycle with ad libitum food and water access. Experiments were performed in accordance with the German law on the use of laboratory animals.

\section{Organotypic Slice Cultures and Heat-Shock}

Rat hippocampal slice cultures were used for heat-shock studies. All solutions used for organotypic slice culture preparation were sterile, and all preparations were performed in a laminar air flow bench with horizontal counter flow (Heraeus Instruments, Hanau, Germany). Five-days-old wistar rats (P5) were decapitated, and the hippocampus was dissected out and gently placed on the platform of a Mcllwain tissue chopper. The hippocampus was cut perpendicular to the longitudinal axis into $400 \mu \mathrm{m}$ thick slices, which were transferred into incubation solution at $4{ }^{\circ} \mathrm{C}$ (Gey's Balanced Salt Solution containing 10\% Kynurenine and $45 \% \mathrm{D}$-glucose). After $1 \mathrm{~h}$ of recovery, the slices were transferred to a separate membrane insert (Millicell $0.4 \mu \mathrm{m}$ culture plate inserts, $30 \mathrm{~mm}$ diameter; Merck Millipore) and subjected to a different experimental condition (i.e., one slice of each pair served as a control, whereas the corresponding slices were subjected to experimental treatment). The cultures were incubated in vitro in a $37^{\circ} \mathrm{C}, 5 \% \mathrm{CO}_{2}$ humidified incubator; $100 \mathrm{ml}$ culture medium consisted of 50\% MEM, 25\% Hank's balanced salt solution, and 25\% heat-inactivated horse serum, supplemented with $1 \%$ glutamine $(200 \mathrm{mM}), 1.56 \%$ glucose ( $45 \%$ in aqua dest.), $0.58 \% \mathrm{NaHCO}_{3}$ (7.5\%, HyClone GE Healthcare), 1\% penicillin, and streptomycin (Thermo Fisher Scientific/Invitrogen). To simulate a fever situation in vitro, heatshock of the cultures started at DIV 3. Thus, the incubation temperature for the hippocampal slice cultures was increased to $41^{\circ} \mathrm{C}$ for $6 \mathrm{~h}$ to achieve hyperthermia. Next, the slice cultures were again incubated at $37^{\circ} \mathrm{C}$ for 2 more days. Slices were subsequently fixed with $4 \%$ paraformaldehyde (PFA) in phosphate buffer (PBS) 
for $90 \mathrm{~min}$. After that, the hippocampal sections were washed and transferred in PBS. The outcome was compared with the control slice cultures exposed all days at $37^{\circ} \mathrm{C}, 5 \% \mathrm{CO}_{2}$.

\section{Immunohistochemistry and Image Capture}

The collected slice cultures in PBS were subsequently processed free-floating and all incubations were performed darkened on a shaker. For immunostaining, tissue sections were permeabilized in $0.1 \%$ Triton-X-100 in PBS for $1 \mathrm{~h}$ at room temperature and then pre-incubated with blocking solution (5\% normal goat serum, $1 \%$ BSA in $0.1 \mathrm{M}$ PBS, $0.1 \%$ Triton-X-100) overnight at $4^{\circ} \mathrm{C}$. After washing $3 \mathrm{x}$ in $0.1 \mathrm{M}$ PBS for $10 \mathrm{~min}$, sections were incubated in primary antibodies diluted in $0.1 \mathrm{M}$ PBS for two nights at $4^{\circ} \mathrm{C}$. The following primary antibodies were used: rabbit polyclonal anti-Iba-1 (1:500; Wako Pure Chemical Industries, Osaka, Japan) or mouse monoclonal anti-ED-1 (1:250; Abcam $^{\circledR}$, Cambridge, United Kingdom). After primary antibody incubation, sections were washed twice in $0.1 \%$ Tween-20 in PBS and once in PBS for $5 \mathrm{~min}$, before secondary antibodies were applied for $3 \mathrm{~h}$ at room temperature: Alexa Fluor 594coupled goat anti-rabbit IgGs (1:400; Invitrogen, Frankfurt, Germany) or Alexa Fluor 488-coupled goat anti-rabbit IgGs (1:400; Invitrogen). Sections were washed again and treated with the primary antibodies diluted in $0.1 \mathrm{M}$ PBS overnight at $4^{\circ} \mathrm{C}$ : anti-Reelin (1:1000; Medical \& Biological Laboratories Co., Tokyo, Japan) or anti-Prox-1 (1:1000; AngioBio Co., San Diego, CA, United States). After washing, they were incubated with secondary antibodies conjugated with Alexa 488 or 594 fluorophores (1:400) for $2 \mathrm{~h}$ at room temperature. Nuclei were counterstained with the fluorescent dye 4',6-diamidino2-phenylindole (DAPI) (1:1000; Roche Diagnostics GmbH, Mannheim, Germany). Finally, after three repetitive washing with PBS, free-floating sections were mounted on glass slides. All sections were embedded with fluorescent mounting medium (Carl Roth $\mathrm{GmbH} \&$ Co. Kg, Karlsruhe, Germany), coverslipped, and subsequently viewed and photographed using confocal fluorescence microscope (Nikon Spinning Disk). For image acquisition and quantification, a $20 \mathrm{x}$ air- and $60 \mathrm{x}$ watermagnification immersion objective was used. The sections were also processed by using the ImageJ $1.52 \mathrm{k}$ software. To control for specificity, sections were processed according to the protocol above with primary antibodies omitted.

\section{Measurement of Granule Cell Layer Width}

To evaluate a potential GCD in the dg, three different approaches with ImageJ were used. The average width of the gcl was measured by length measurement (1) according to Houser (1990), by counting the number of cells covering a $75 \mu \mathrm{m}$ standard ruler (2), and by evaluation of the area of intercellular space in the gcl (3). The average width of the gcl of the $\mathrm{dg}$ was determined in DAPI- and Prox-1-stained sections of heatshock-treated and control hippocampi in each subregion. (1) The perpendicular distances from the inner (hilar) border of the gcl to the outer border of the most distal granule cell somata were determined by DAPI and Prox-1 immunostaining and using ImageJ (Figure 1). The mean and SD of three regions of interest in three optical z-sections were calculated for each case. (2) For more precise analysis, a fixed line (ruler) with a defined length $(75 \mu \mathrm{m})$ was placed perpendicularly to the gcl over each subfield at defined intervals (Figure 2). To quantify the width of the gcl, only granule cells in proximity to or in contact with the standard ruler were chosen. Cells were excluded from quantification when the cell body was not positioned on the fixed line. (3) The intercellular space within the gcl was calculated automatically in a threshold dependent manner by using ImageJ. Thereby, the intercellular space of the gcl was compared between matched slices of the same animal, i.e. between control and after heat shock. In each of the three positions [suprapyramidal blade (SB), crest (C), and infrapyramidal blade (IB)], a fixed region of interests (circle) was placed three times per region in the gcl and intercellular space was calculated (illustrated in Figure 3). To find out whether the heat-shock caused a generalized tissue expansion of the hippocampal slice culture, we measured the shortest distance between the SB of the gcl and the CA1 pyramidal cell layer in a standardized manner. Next, we compared the area of the gcl and hilar region in control and heat-shock-treated slice cultures by measuring the pixel area size with standard implemented features in ImageJ and normalized the area size after heat-shock to the area size of the matched control slice.

\section{Cell Quantification}

For quantitative analysis of cell distribution in hippocampal slice cultures, identical illumination for each section by a photographer who was blinded to the experimental condition was used. High-resolution images acquired with a $60 \mathrm{x}$ water immersion objective (Nikon 60xA/1.20) within subfields of the $\mathrm{dg}$ ( SB, C, and IB; white boxes indicate the areas of interest in Figures 4A,D) in particular of the molecular (mol) and the gcl were taken for visual cell counts. For further analysis (also blinded), two pictures per hippocampal subregions in three z-levels were chosen.

The total number of cells was counted visually in optical sections by staining with DAPI. Individual cell counts were achieved by staining with cell specific markers. Thus, quantitative analysis of different cell types in the dg subfields (SB, C, and IB) was perfomed by counting cells that were immunopositive for CR-50 (CR-cells), Prox-1 (granule cells), Iba-1 or ED-1 (microglia), respectively. Cell numbers were normalized to the total number of DAPI stained cells per image subfield.

Reelin positive interneurons were manually counted in optical sections from matched slices of five different animals per experimental condition.

Propidium iodide (PI) staining was performed by applying $200 \mu \mathrm{l} / \mathrm{ml}$ of a $500 \mathrm{nM}$ PI solution to living cell cultures $1 \mathrm{~h}$ before fixation with PFA. Slice cultures were then co-stained with Prox-1 as described earlier. Cell counts of PI positive cells in the gcl were achieved visually by an experimenter blinded to the experimental condition in one exemplary z-level of a slice.

\section{Statistical Analysis}

Statistical analyses were performed with GraphPad Prism version 7.00 (GraphPad Software Inc., San Diego, CA, United States) and 

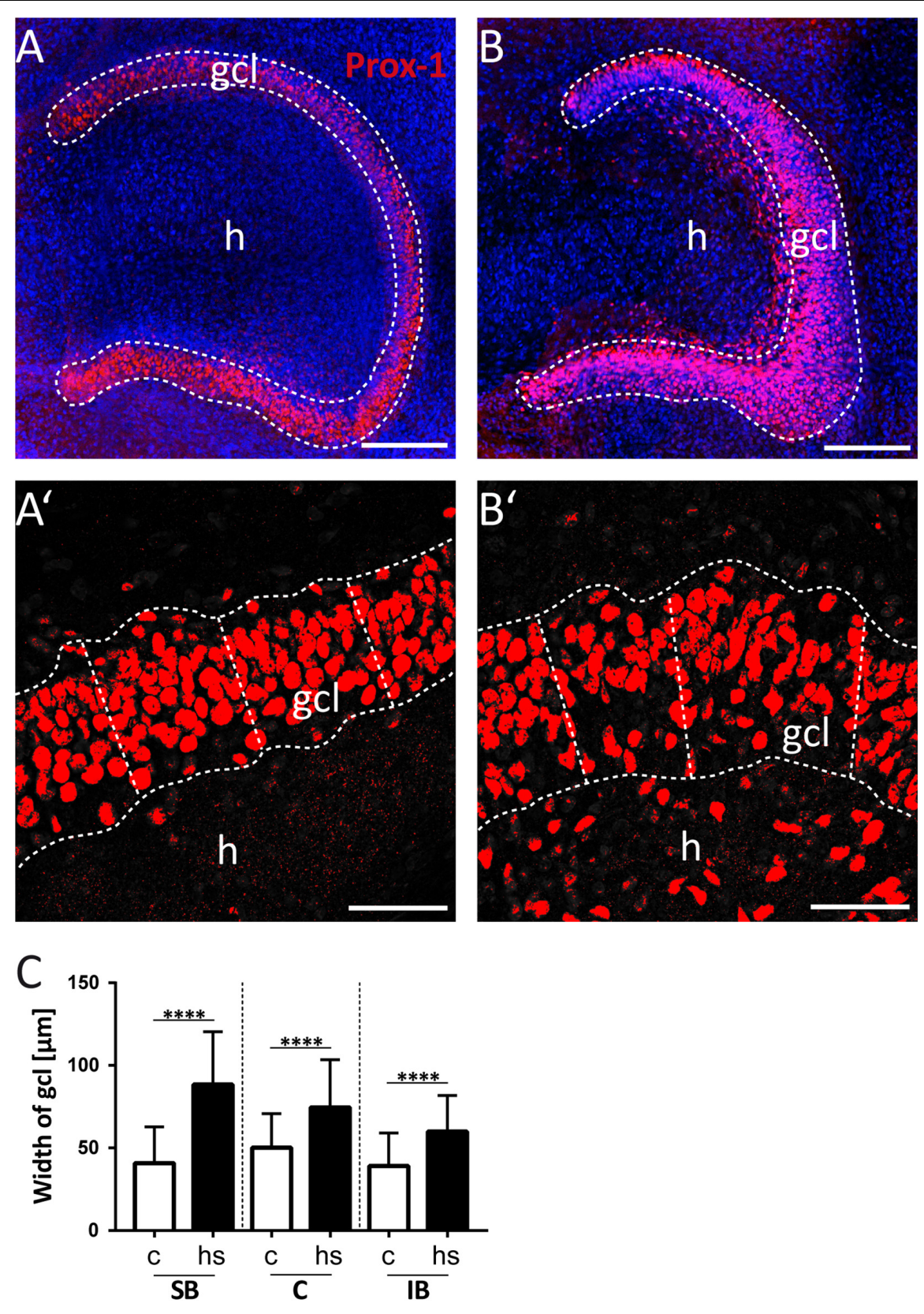

FIGURE 1 | Heat-shock increases the width of the granule cell layer (gcl). (A) Prox-1 immunopositive staining under control condition and (B) after heat-shock. (A', B') The width of the granule cell layer was determined by measuring the shortest distance from Prox-1 immunostained (red) granule cell nuclei at the inner (hilar) border of the gcl to the most distal granule cell nuclei neighboring the molecular layer. Prox-1-stained nuclei with a distance of more than $30 \mu \mathrm{m}$ from the granule cell layer were excluded from the measurements. Slices were counterstained with the nuclear dye DAPI (blue). (C) The mean and the standard deviation of three regions of interest (see Figures 4A,D) in three optical z-sections were calculated for each case and showed a significant increase in width of the granule cell layer after heat-shock (hs) compared to control (c) independent of the region of interest. Asterisks indicate significance for $p<0.05$. gcl, granule cell layer; h, hilus. Scale bar (A,B): $200 \mu \mathrm{m} ;\left(\mathbf{A}^{\prime}, \mathbf{B}^{\prime}\right): 50 \mu \mathrm{m} ; n=9$.

in Microsoft Excel. For analysis, slices from the same animal incubated as control or treated as heat-shock were tested as pairs of groups. These pairs of groups were tested for normal distribution (D'Agostino test and Shapiro-Wilk test) and if so a paired Student's $t$-test was performed. In the case of non-normal distribution of the raw data, the Wilcoxon-Mann-Whitney test was used for statistics. Values were considered statistically significant at $p<0.05$. Statistics reported in the text and figures are represented either by mean value and standard deviation or by boxplots giving the median (middle dash), the lower and upper quartile (box borders), and the minimum and maximum values (whiskers). 

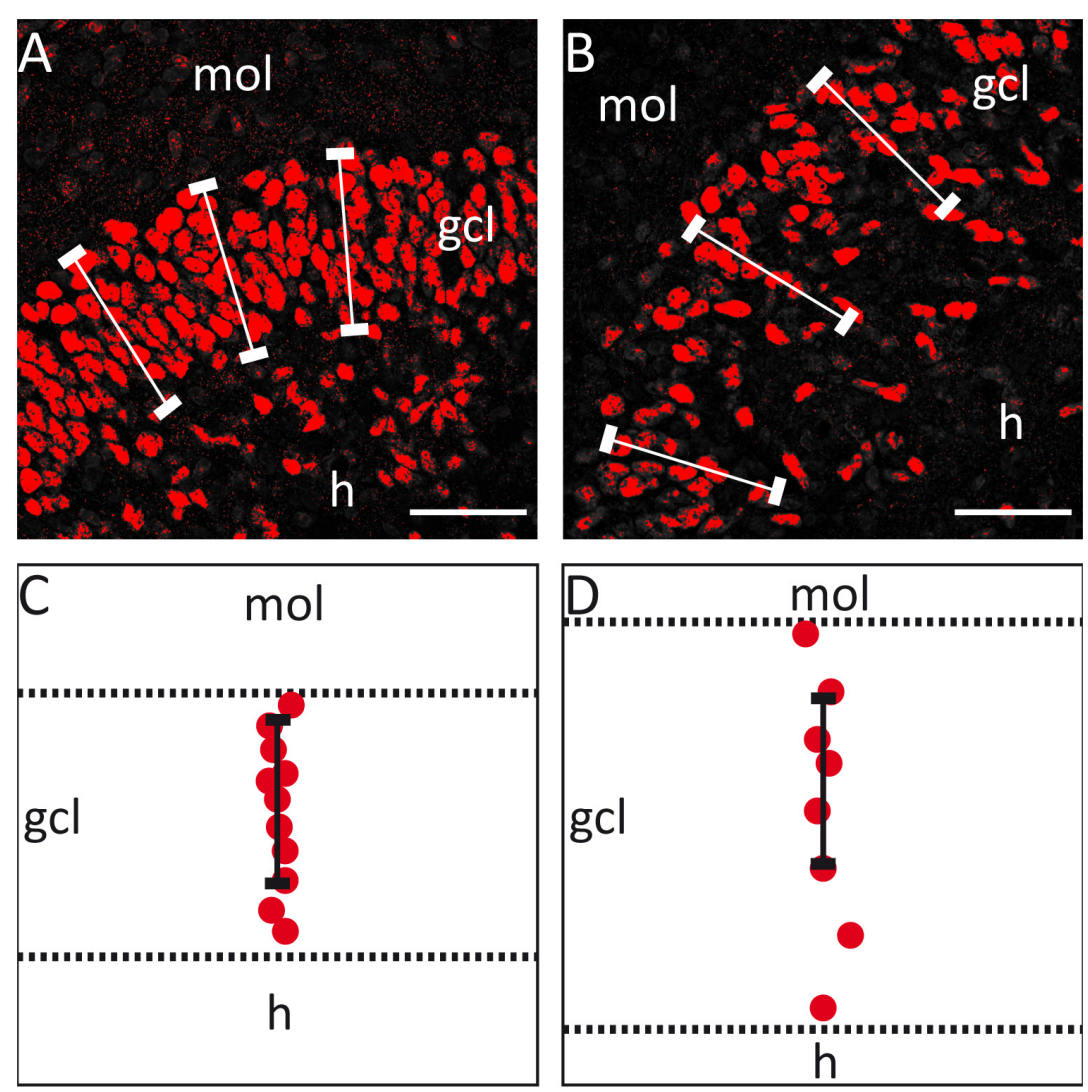

E
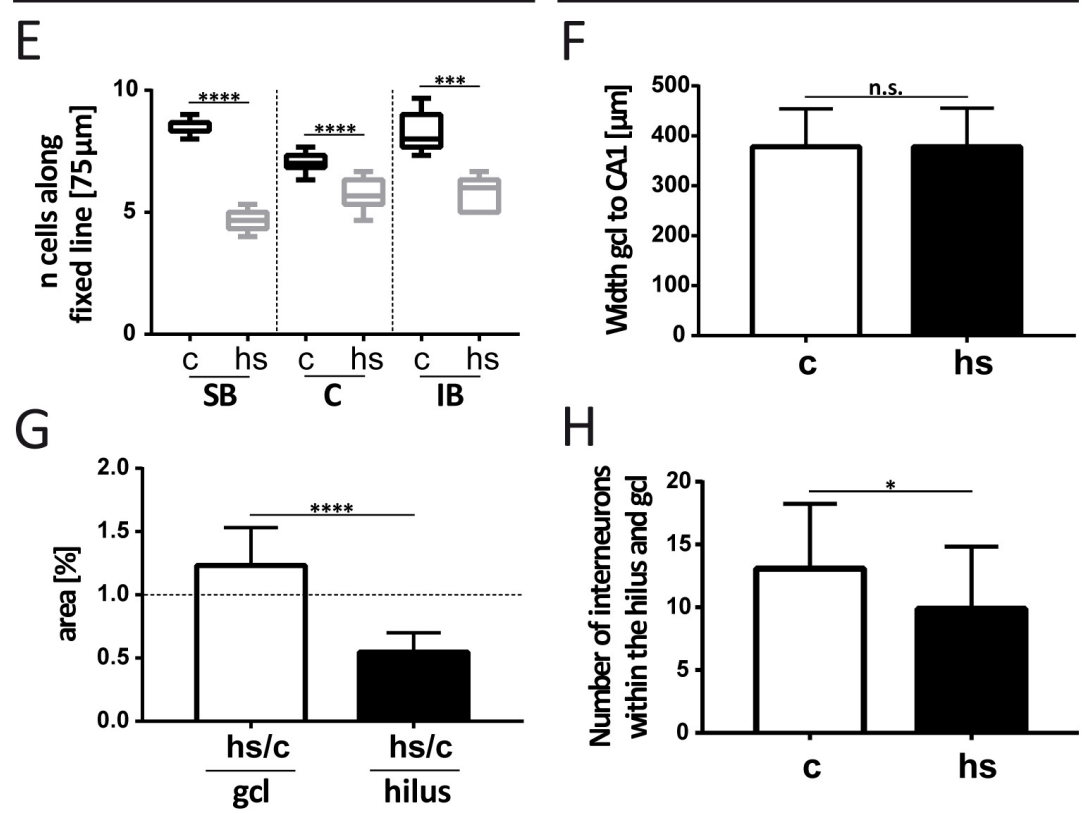

FIGURE 2 | Analysis of heat-shock-induced granule cell dispersion. For counting of Prox-1 immunostained granule cells (red), standard rulers (fixed lines) of $75 \mu$ m length were positioned into confocal images of the granule cell layer of control slices (A) and after heat-shock (B). Schematic drawings (C, control; $\mathbf{D}$, heat-shock) illustrate that the cell number that is covered by such a ruler is reduced after heat-shock, indicative of granule cell dispersion. (E) Counting of cells covered by rulers positioned in different subregions of the granule cell layer (gcl) showed a decrease in the number of granule cells in all subregions. Boxplots with median, $25 \%$ and $75 \%$ quartile, minimum, and maximum are shown. $n=9$. (F) The shortest distance from the granule cell layer to the CA1 pyramidal cell layer region was determined in a standardized manner by measuring the shortest distance of the intermediate part of the gcl suprapyramidal blade (SB) to the intermediate part of the CA1 pyramidal cell layer. This distance did not change between control- (c) and heat-shock-treated slices (hs). $n=9$. (G) However, when comparing the surface area covered by gcl and hilus in control and heat-shock-treated slices, the gcl area was significantly increased, while the hilus area was significantly decreased. $n=9$. (H) Cell counts revealed a slight, but significant reduction of Reelin positive interneurons after heat-shock in the area covered by the hilus and gcl. $n=5$. Asterisks indicate significance for $p<0.05$. mol, molecular layer; h, hilus; C, crest; IB, infrapyramidal blade. Scale bar (right lower corner): $50 \mu \mathrm{m}$. 

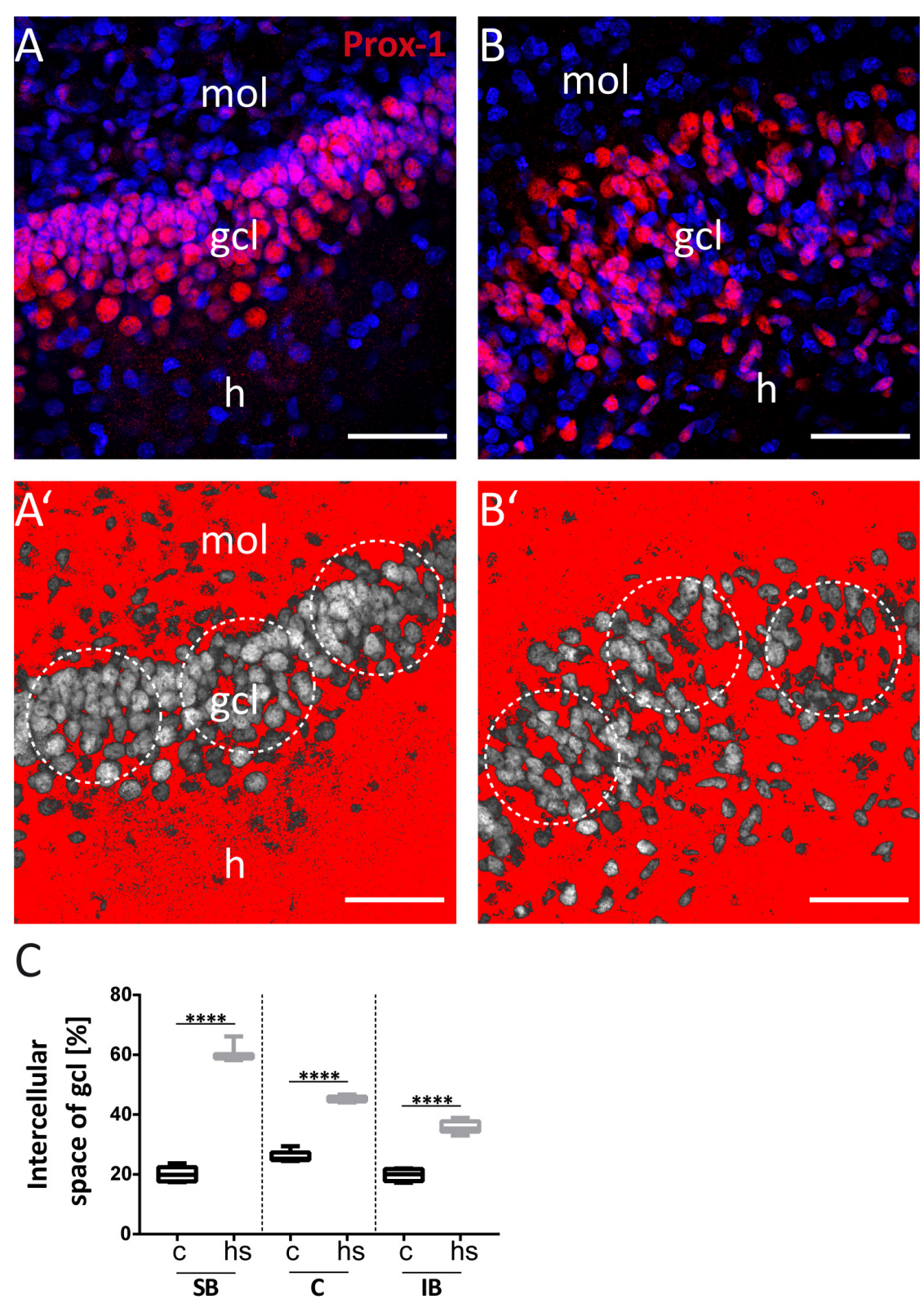

FIGURE 3 | Increase of extracellular space in the granule cell layer after heat-shock. Representative Prox-1 immunostaining of granule cells (red) under control conditions (A) and after heat-shock (B). Same images are shown with a threshold dependent mask (red) around granule cells (gray) (A', control; B', heat-shock). Circular masks (white dotted circles) were used to measure the approximate area increase between cells after heat-shock compared to control (C). Boxplots with median, 25\% and 75\% quartile, minimum, and maximum. $n=9$. Asterisks indicate significance when $p<0.05$. gcl, granule cell layer; mol, molecular layer; h, hilus. Scale bar: $50 \mu \mathrm{m}$.

\section{RESULTS}

\section{Heat-Shock Induces Granule Cell Dispersion in Hippocampal Slice Cultures}

To study the impact of a heat-shock on the morphology of the $\mathrm{dg}$, we first analyzed the width of the gcl in matched hippocampal slice cultures after heat-shock and in untreated control cultures
(Figures 1A,B) by measuring the perpendicular distance from the inner (hilar) edge of the gcl to the most distal granule cell somata bordering the dentate molecular layer (Figures 1A',B') (Houser, 1990). This measurement revealed a highly significant increase in width of the gcl after heat-shock, of $47.6 \mu \mathrm{m}$ for the $\mathrm{SB}$ region, of $24.4 \mu \mathrm{m}$ for the $\mathrm{C}$ region, and of $20.9 \mu \mathrm{m}$ for the IB region (Figure 1C, $\mathrm{c}=$ control, hs = heat-shock). Next, we used two different approaches to quantify this change of width of the gcl (Figures 2,3). Thus, we first counted the number of 

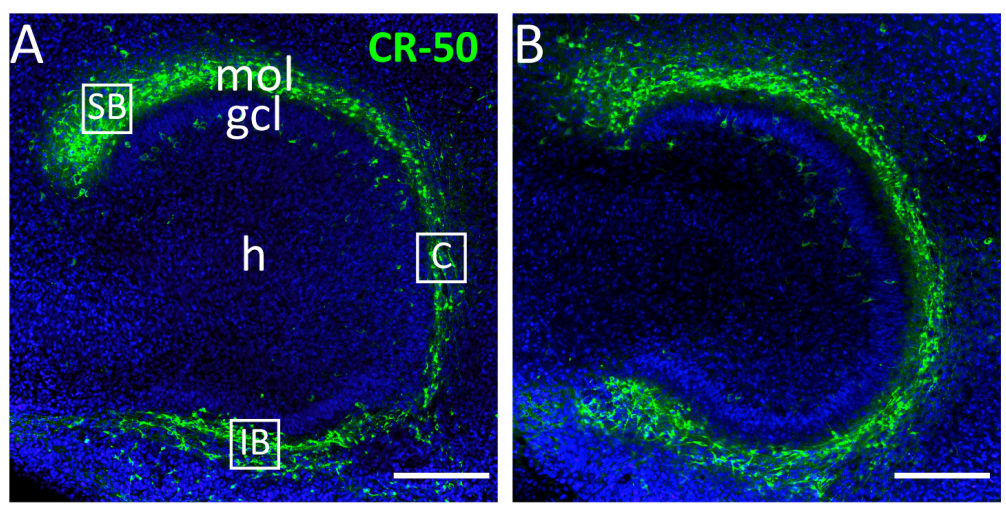

\section{C \\ molecular layer}
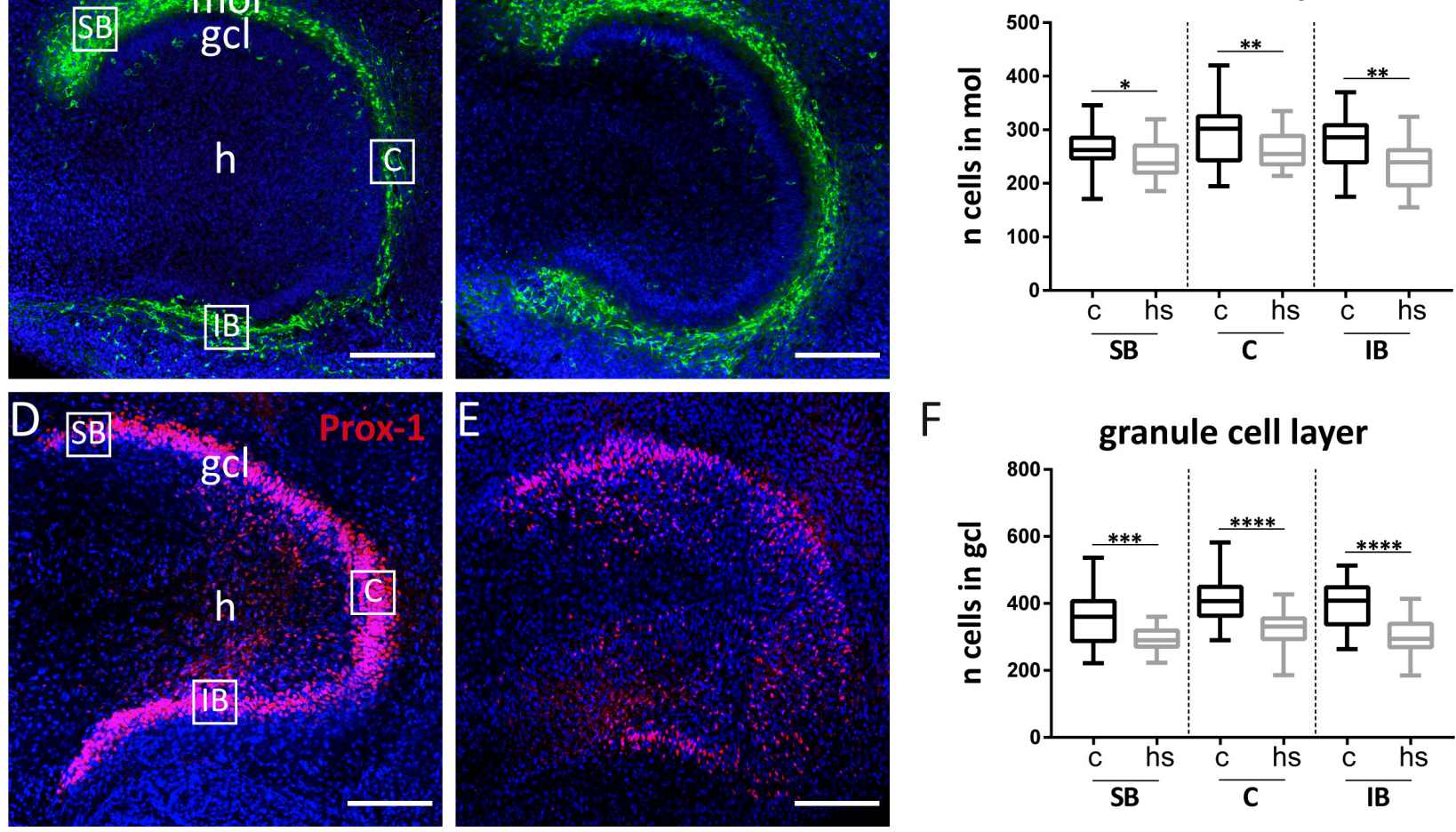

$\mathrm{F}$

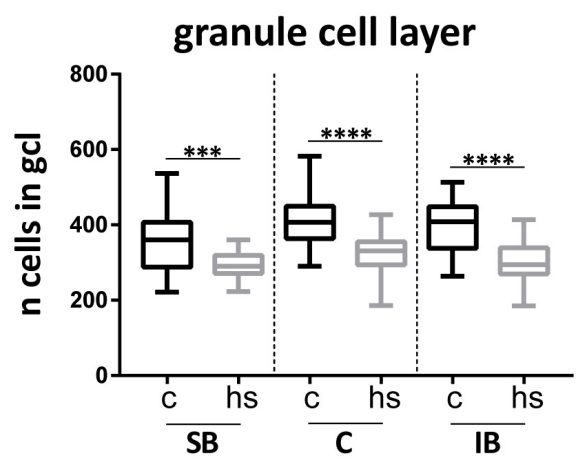

FIGURE 4 | Effect of heat-shock on cell viability in hippocampal slice cultures. (A) Representative immunofluorescent staining against Reelin (green) of control hippocampal slice culture. Cajal-Retzius (CR) cells in the molecular layer (mol) of the dentate gyrus appear green. White squares enclose three subregions of interest within the mol, which were chosen for cell counting (same, enlarged areas of interest are shown in Figure 5). (B) CR-50 staining against Reelin (green) of a heat-shock-treated hippocampal slice culture. (C) Quantification of DAPI positive cells in the dentate molecular layer in control slice cultures (c) and after heat-shock (hs). (D) Prox-1 immunostaining visualizing granule cells (red) in a control hippocampal slice culture. (E) Prox-1 immunostaining in dentate gyrus after heat-shock. Note that the compactness of the granule cell layer (gcl) is lost. Nuclei are counterstained with DAPI (blue) in all images. Quantification of CR-cells within regions of interest (SB = suprapyramidal blade, $\mathrm{C}=$ crest region, and IB = infrapyramidal blade) is shown in (A), squares were positioned on the gcl for granule cell counts and quantified in the same way (D). After heat-shock, the total cell number decreases significantly independent of its position in mol or gcl, although a stronger reduction is seen in the $\mathrm{gcl}$ (F) compared to the mol (C). Boxplots show median, $25 \%$ and $75 \%$ quartile, minimum, and maximum. $n=27$. Asterisks indicate significance for $p<0.05$. gcl, granule cell layer; $h$, hilus. Scale bar: $200 \mu \mathrm{m}$.

granule cells that a ruler of $75 \mu \mathrm{m}$ length encompassed in the gcl under control condition (Figure 2A) and after heat-shock (Figure 2B). Hyperthermia significantly reduced the number of granule cells that were encompassed by the ruler in all analyzed subregions (SB, C, and IB) of the dentate gcl (Figure 2E). This result is schematically illustrated in Figures 2C,D, indicating a reduction of the cell number in the gcl and an increase in width. Note that ruler encompassed the entire width of the gcl in control slices but not after heat-shock (compare Figures 2A,B and $\mathbf{C , D}$ ). The distance between the gcl and CA1 pyramidal cell layer showed no difference between matched slices of control and heat-shock-treated cultures (Figure 2F). However, when measuring the gcl area of heat-shock-treated cultures normalized to the gcl area of untreated controls from matched slices, we found the area of the gcl increased by $23 \%$ whereas the area of the hilus in the same slice decreased by $45 \%$ (Figure 2G). Counting of Reelin expressing hilar interneurons revealed that the number of interneurons was slightly, but significantly reduced after heat-shock (Figure 2H). Next, we analyzed the apparent expansion of the extracellular space between granule cells after heat-shock. For quantification, we positioned a circular mask into the dentate gcl, calculated the extracellular space between the cells within the circle in an automatized threshold-dependent manner (Figures $3 \mathbf{A}^{\prime}, \mathbf{B}^{\prime}$ ), and normalized to the total area of the circular mask. Figure 3 shows Prox-1 positive staining of untreated granule cells (Figure 3A) and of granule cells after heat-shock (Figure 3B) in the SB of the gcl. Comparison of these images visualizes the reduced cell packaging in the gcl after heatshock. This revealed a significant increase in extracellular space after heat-shock treatment (Figure 3C).

\section{Survival of Dentate Granule Cells but Not of CR Cells Is Impaired After Heat-Shock}

To analyze a potentially deleterious effect of the heat-shock on survival of dentate granule cells, we determined the total cell number in confocal images of the gcl and mol in hippocampal slice cultures in control slices and after heat-shock (Figure 4) by counting DAPI positive nuclei. These counts revealed a highly significant reduction of the cell number in the mol 
(Figure 4C) and gcl after heat-shock (Figure 4F). To identify individual cell types, slices were immunostained with a Reelinspecific antibody to label CR cells (Figures 4A,B) and with an antibody against Prox-1 (Prospero homeobox protein 1) to label dentate granule cells (Figures 4D,E). High-resolution confocal scanning of different representative areas within the dg was performed (Figures 4A,D; SB, C, and IB) and immunostaining against Reelin and Prox-1 allowed for counting of individual cell types in the $\mathrm{dg}$ of control (Figures 5A,D) and after heat-shock (Figures 5B,E). Surprisingly, cell counts for Reelin positive CR cells within three representative areas of the dentate molecular layer (SB, C, and IB) showed no significant difference after heat-shock (Figure 5C), whereas the number of Prox1 positive granule cells was significantly reduced (Figure 5F). Next, we quantified dying cells by counting the number of PI positive pyknotic nuclei of cells in the gcl after heat-shock (Figure 6). In control slices, only few cell nuclei were found to be PI positive (Figure $\mathbf{6 A}$, red) surrounded by numerous Prox-1 positive cells (Figure 6A, green). In contrast, after heatshock, many PI positive cell nuclei appeared (Figure 6B, red) in the gcl and quantification confirmed that this increase was significant (Figure 6C).

\section{Microglia Response to Heat-Shock in the Dentate Gyrus of Slice Cultures}

Microglial cells can actively migrate to lesion sites with ameliorating effects supporting recovery after lesion (Kettenmann et al., 2011; Sieger et al., 2012; Eyo and Dailey, 2013). The ionized calcium-binding adapter molecule 1 (Iba-1) is a commonly used marker for microglia. Combination of the antibodies Iba-1 and CR-50 against Reelin allowed to analyze the impact of the microglia response to heat-shock in the dg. Figure $7 \mathrm{~A}$ shows that under control conditions, microglial staining with an antibody against Iba- 1 is sparse in both the gcl and the mol (enlargement of mol shown in Figure 7A', indicated by the boxed area in Figure 7A). After heat-shock, the slice cultures show a strong increase of Iba-1 positive staining in the mol (Figure 7B, enlargement in B'). Microgliosis is also evident in the hilar region and pyramidal cell layer of the hippocampus (Figure 7B). Counting of microglia cells based on Iba-1 positive staining show a significant increase in microglia by more than twofold in all three analyzed $\mathrm{dg}$ subregions (Figure 7C). To count microglia in the gcl before treatment (Figures $\mathbf{8} \mathbf{A}, \mathbf{A}^{\mathbf{\prime}}$ ) and after heat-shock (Figures 8B,B'), the ED-1-antibody against the cluster of differentiation protein (CD68) was used to label microglia in combination with a Prox-1 antibody to visualize granule cells. As already shown in the previous experiment, only few microglia cells were detected in hippocampal sections under control conditions, particularly in the gcl (Figure $\mathbf{8 A}$, white square in Figure 8A depicts the boxed area in Figure 8A'). Only few ED-1 positive cells were detected at the inner border of the gcl to the hilar region (Figure $\mathbf{8} \mathbf{A}^{\mathbf{\prime}}$ ). This changes significantly after heat-shock, as can be seen in Figure 8B (and in magnification in Figure 8B'), showing an increased intensity of immunostaining against CD68 protein (ED-1, green), indicative of massive microglia invasion into the gcl and adjacent areas. Quantification of microglia cells in this cell layer also showed a significant increase more than threefold in all three investigated subregions of the dg (Figure 8C).

High-magnification images of heat-shock-treated microglia stained against the Iba-1 protein demonstrate that the increased microglia staining resulted, at least in part, from mitotic cell divisions (Figures 9A,B). Numerous dividing cells were found in the $\mathrm{dg}$ of heat-shock-treated slice cultures. In addition, numerous actively phagocytizing microglia cells were found within heatshock-treated hippocampal slice cultures (Figures 9C,D).

\section{DISCUSSION}

Ammonshorn sclerosis and/or dispersion of dentate granule cell are frequently observed in epileptic hippocampal tissue, and febrile seizures early in life are suspected to be causally linked to these pathologies. Loss of Reelin, a protein known to control neuronal migration during development, has been discussed as a possible cause of pathological GCD. In turn, recent findings suggest that GCD may not always be disease related but could instead reflect normal morphological variation. For instance, the presence of newborn granule cells within the dentate hilar region during early dg development reflects the normal development of this region but could be misinterpreted as pathological GCD. Thus, the interpretation of GCD in a diseaserelated context remains controversial. To explore the potential impact of febrile temperature on granule cells and Reelin secreting CR cells, hippocampal slice cultures were subjected to a transient temperature increase (heat-shock). We found that a heat-shock caused both dentate GCD and degeneration of a fraction of granule cells. Surprisingly, the viability of CR cells was not affected. This precludes that heat-shock-induced GCD was related to depletion of the $\mathrm{CR}$ cell population. We also found that the heat-shock caused a massive increase in the number of microglial cells in the $\mathrm{dg}$, indicating a robust immune response to the heat-shock-induced tissue damage.

\section{Granule Cell Dispersion in Development and Disease}

A developmental peculiarity that distinguishes dg (archicortical) development from neocortical development is the emergence of three consecutive germline matrices during dg development. In the tertiary proliferation zone located in the hilar region of the early postnatal dg, proliferating progenitors generate granule cells which migrate from the hilar region to their final positions in the compact gcl (Altman and Das, 1965; Sugiyama et al., 2013; Hayashi et al., 2015). Thus, the transient distribution of newborn granule cells in the hilar region is a normal stage of early postnatal dg development but could be easily mistaken as pathological GCD. Also in the reeler mutant mouse which does not express the extracellular matrix protein Reelin, dentate granule cells are formed in the tertiary proliferation zone, but fail to migrate properly to form a compact gcl and therefore remain dispersed in the dentate hilar region throughout life (Stanfield and Cowan, 1979; D'Arcangelo et al., 1997; Forster et al., 2006a). GCD has also been observed in resected hippocampal 

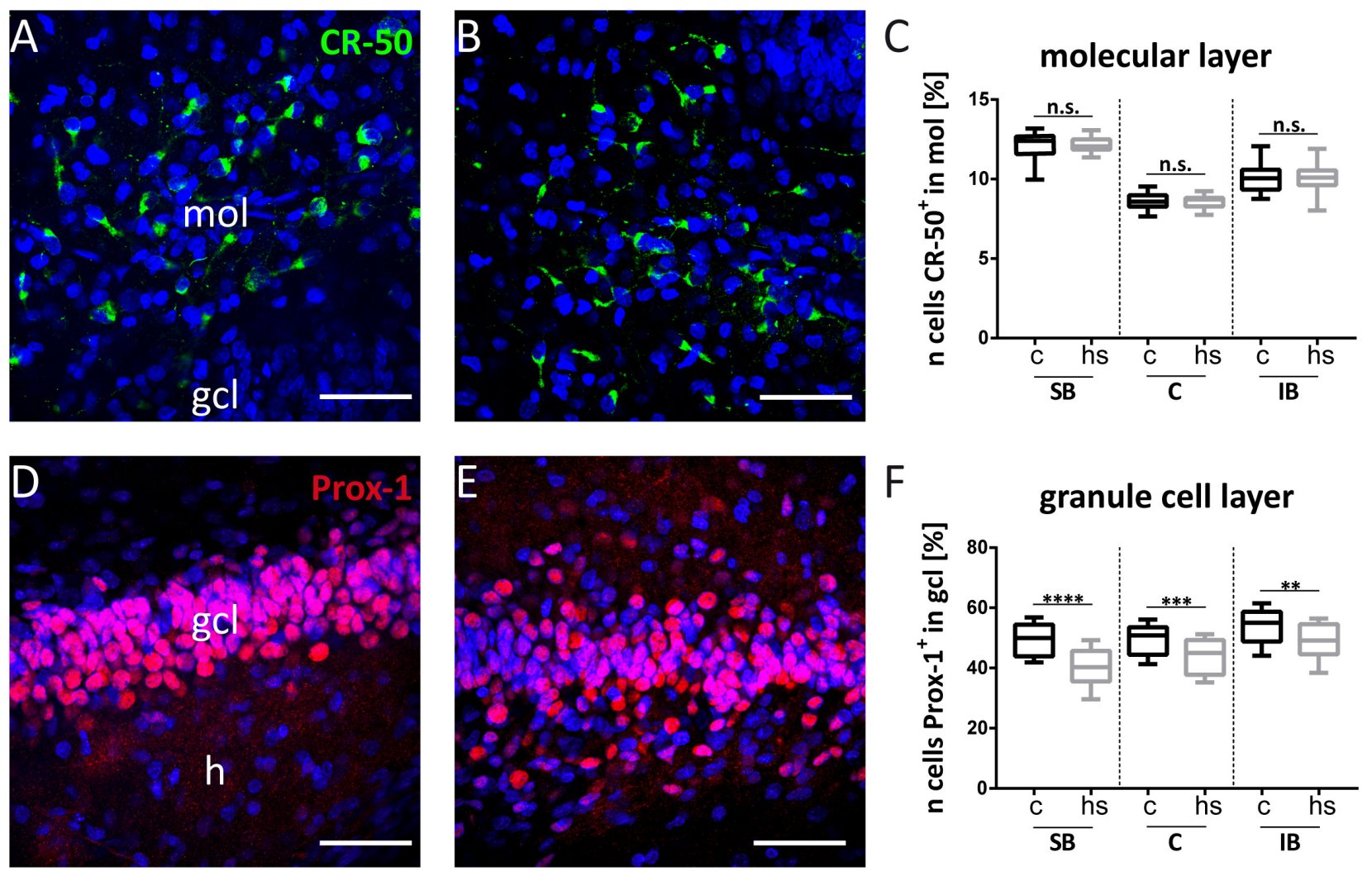

FIGURE 5 | Heat-shock reduces the number of granule cells but not of CR cells. Exemplary, high magnifications of CR (green) cells immunostained against Reelin are shown within the dentate suprapyramidal blade under control condition (A) and after heat-shock (B). Prox-1 immunostained granule cells (red) are shown in a control slice (D) and after heat-shock (E). Counts of CR cells within the molecular layer (mol) show comparable cell numbers (C), whereas granule cell counts revealed a significant reduction in all subregions of the dentate granule cell layer (gcl) investigated (F). Boxplots with median, $25 \%$ and $75 \%$ quartile, minimum, and maximum. $n=27$. Asterisks indicate significance for $p<0.05$. gcl, granule cell layer; $\mathrm{h}$, hilus. Scale bar: $50 \mu \mathrm{m}$.

tissue of patients with TLE, often associated with ammonshorn sclerosis (Houser, 1999; Haas and Frotscher, 2010). Since an inverse correlation was found between the number of Reelinexpressing cells in the hippocampus and the extent of GCD in TLE patients, a causal relationship between reduced Reelin availability and GCD had been suggested (Haas et al., 2002; Haas and Frotscher, 2010; Bozzi et al., 2012). In turn, a recent study reported on GCD in the hippocampus of pediatric patients that did not suffer from epilepsy, indicating that GCD, at least at early age, might be within the normal variation range of $\mathrm{dg}$ morphology (Roy et al., 2020). Thus, careful interpretation of the causes that might underlie GCD should take into account that morphological variation or apparent dispersion at early stages might reflect newborn granule cells that migrate from the tertiary proliferation zone to form a compact gcl. Since defined transcription factors, including for example Pax-6 and Prox-1, are successively expressed in granule cells and their precursors during dg development (Sugiyama et al., 2013), analysis of transcription factor expression may be useful to distinguish pathological from normal developmental GCD. Characteristic pathological GCD that is clearly not related to development, but pathology-related, has been described in rodents in vivo after administration of the epilepsy inducing drugs pilocarpine
(Gong et al., 2007; Curia et al., 2008) or kainic acid (Haas et al., 2002; Heinrich et al., 2006; Antonucci et al., 2009; Duveau et al., 2011).

\section{Heat-Shock-Induced Granule Cell Dispersion in Hippocampal Slice Cultures}

We wondered whether a transient temperature increase might be sufficient to induce GCD in vitro, and therefore we subjected hippocampal slice cultures from young postnatal rats to a heatshock of $41^{\circ} \mathrm{C}$ for $6 \mathrm{~h}$. Our experiments revealed that this transient heat-shock is sufficient to induce GCD in hippocampal slice cultures. What might be the underlying causes that induce GCD in our in vitro model? For instance, a reduction in the number of Reelin-secreting CR cells, implying reduced Reelin availability, had earlier been shown to be a potential trigger for GCD (Haas et al., 2002; Haas and Frotscher, 2010). Along this line, also kainate induced loss of Reelin expressing hilar interneurons was found to correlate with GCD, suggesting that loss of interneuron-derived Reelin might trigger GCD (Orcinha et al., 2016). Thus, reduced Reelin availability might destabilize the compact $\mathrm{gcl}$ and cause displacement of differentiated 

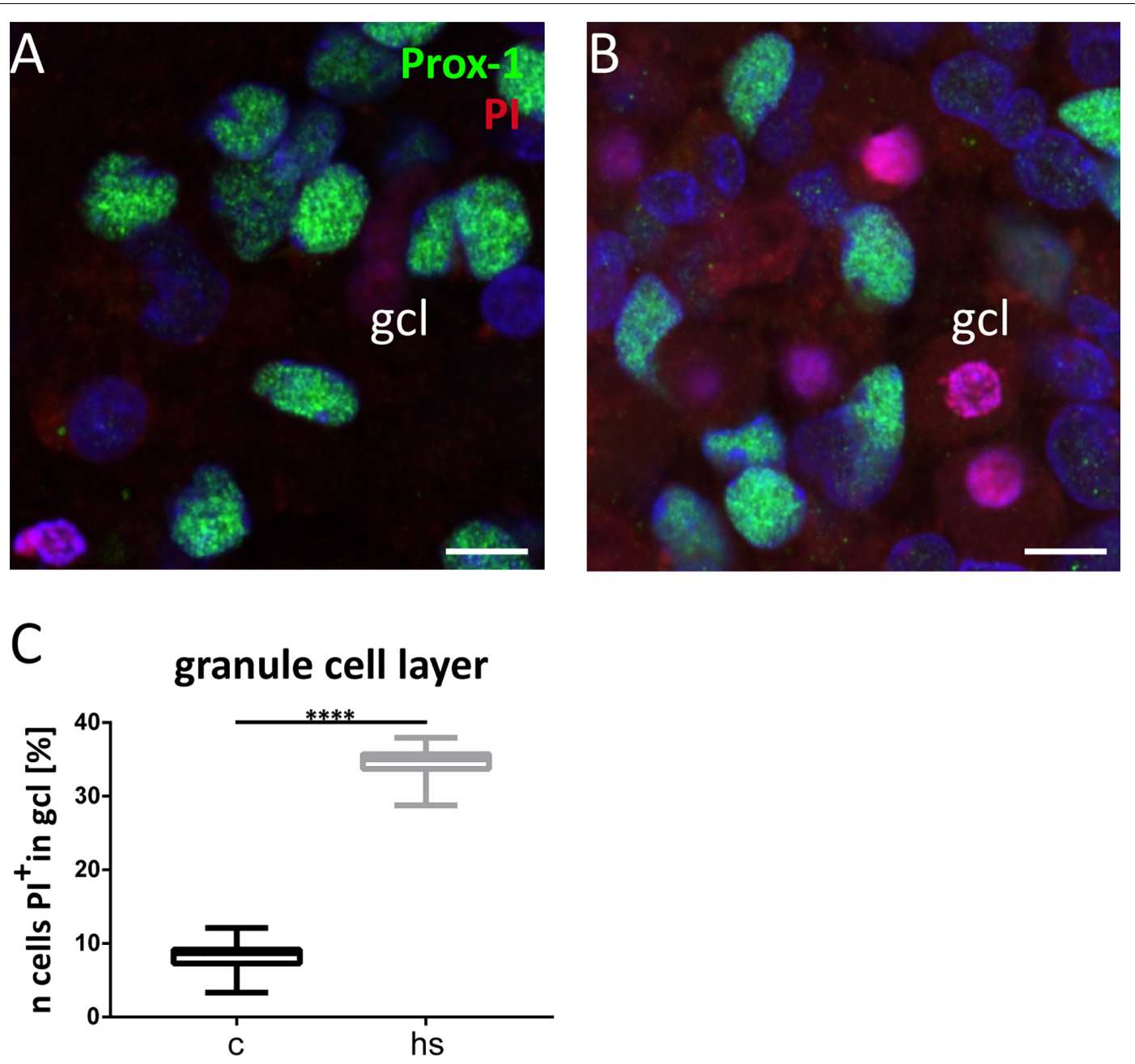

FIGURE 6 | Increased cell mortality in the granule cell layer (gcl). Detail of the gcl visualized by Prox-1 immunostaining of granule cells (green) under control

conditions (A) and after heat-shock (B), combined with propidium iodide (PI) staining of dead cells with pyknotic nuclei (red). Quantification of PI positive cells in gcl (C) revealed a significant increase after heat-shock. Boxplots with median, $25 \%$ and $75 \%$ quartile, minimum, and maximum. $n=30$. Asterisks indicate significance for $p<0.05$. gcl, granule cell layer. Scale bar: $10 \mu \mathrm{m}$.

granule cells toward the hilar region or might fail to prevent overmigration into the dentate molecular layer, which normally does not contain granule cells (Zhao et al., 2004; Hack et al., 2007; Chai et al., 2009; Folsom and Fatemi, 2013). However, in the present study, we were surprised that the size of the CR cell population was unchanged after the heat-shock. Thus, reduced availability of CR cell-derived Reelin is an unlikely cause for heat-shock-induced GCD, though so far we cannot exclude that proteolytic processing of Reelin, which is required for proper Reelin function (Lambert de Rouvroit et al., 1999; Kohno et al., 2009; Haas and Frotscher, 2010; Tinnes et al., 2013), might be affected by the heat-shock. Also reduced Reelin availability due to a decreased number of Reelin expressing hilar interneurons caused by kainate treatment has been hypothesized to be causally linked to GCD (Heinrich et al., 2006; Haas and Frotscher, 2010; Duveau et al., 2011). In our experiments we also found a slight but significant reduction in the number of
Reelin expressing hilar interneurons after heat-shock. However, selective inactivation of Reelin in interneurons of conditional Reelin knock-out mice did not destabilize the gcl (Pahle et al., 2020), arguing against a role of interneuron-derived Reelin in maintaining gcl integrity. Therefore, also other causes that might trigger GCD should be considered. Thus, careful analysis of slice cultures after heat-shock revealed that not only displacement of granule cells, as evidenced by the broadening of the $\mathrm{gcl}$, but also degenerated granule cells, interspersed between the surviving granule cells, contribute to the reduced cell packaging density and to an enlargement of the extracellular space in the gcl. In fact, granule cell loss-induced tissue shrinkage and straining has been hypothesized earlier to be involved in the origin of GCD (Lurton et al., 1997). This indicates that also reorganization of the extracellular matrix may be one of the factors that contribute to pathological dispersion of granule cells. In turn, we can exclude a generalized expansion of the hippocampal slice culture 

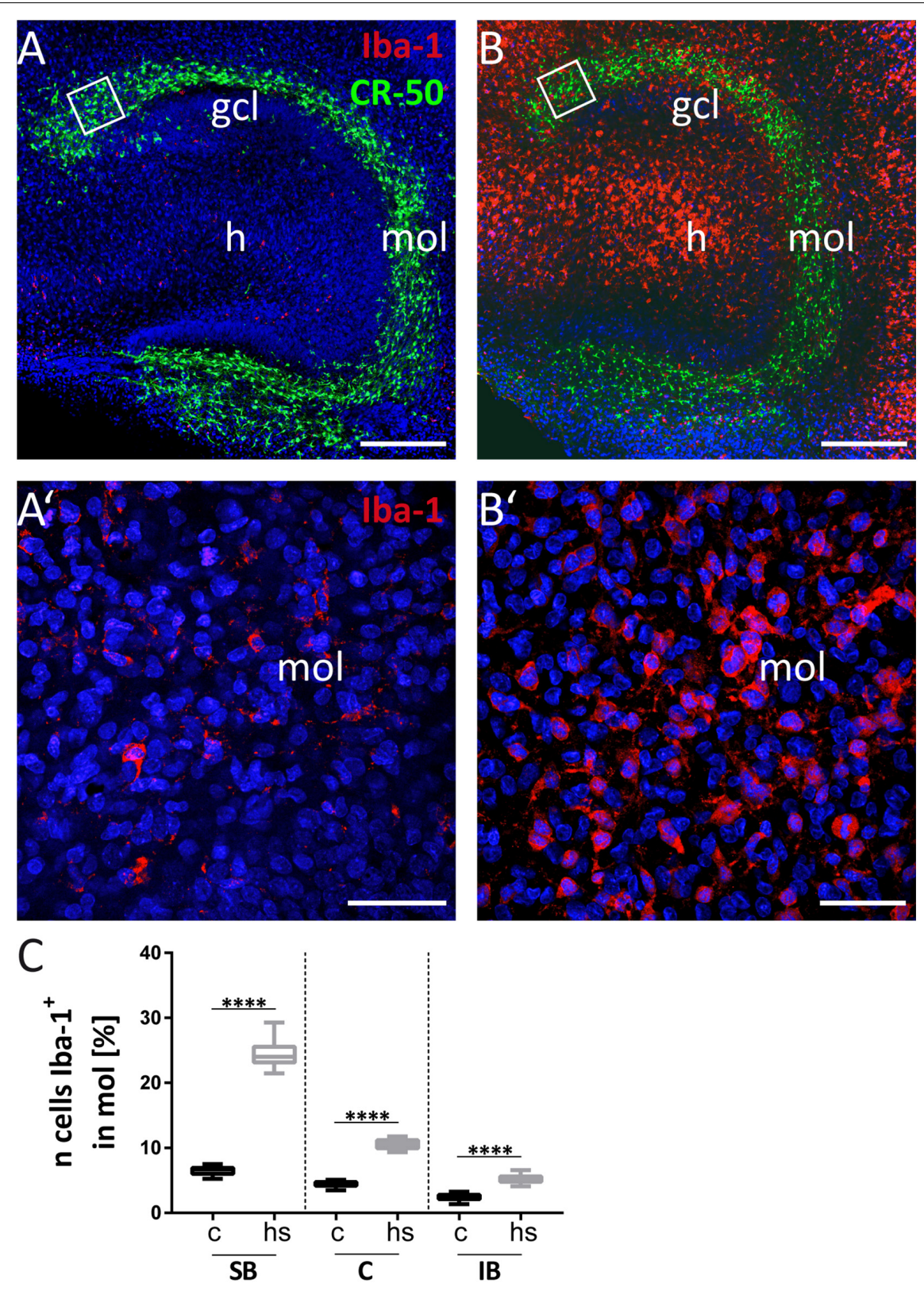

FIGURE 7 | Microgliosis in dentate molecular layer (mol). (A) Reelin immunostaining to visualize CR cells (green) combined with Iba-1 staining (red) to stain microglia

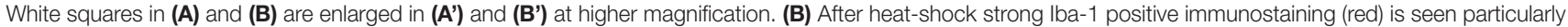
in the hilus (h), but also in the gcl and mol. (A') Only few lba-1 positive microglial cells (red) are seen in the mol in control slices. (B') Numerous microglial cells are detectable by lba-1 staining (red) in the mol after heat-shock. (C) Cell counts in boxed areas of the dentate mol show a significant increase of microglia cells in all subregions investigated. Boxplots are shown with median, $25 \%$ and $75 \%$ quartile, minimum, and maximum. $n=27$. Asterisks indicate significance when $p<0.05$. gcl, granule cell layer; mol, molecular layer; h, hilus. Scale bar (A,B): $200 \mu \mathrm{m}$; (A',B'): $50 \mu \mathrm{m}$.

tissue after heat-shock since the distance between gcl and CA1 pyramidal cell layer did not change after heat-shock.

\section{Granule Cell Dispersion and Seizures}

An important question that is difficult to answer is whether GCD contributes to the development of seizures or rather has an antiepileptic effect. Earlier studies suggested that individuals with GCD have an increased leakage of potassium ions from granule cells which reduces their excitability, pointing to an anti-epileptic effect (Stegen et al., 2009). In turn, mispositioning of granule cells may favor the development of epileptic discharges (Koyama, 2013). On the other hand, recent retrospective studies on hippocampi of pediatric patients with or without seizure history did not show significant differences of cell loss or GCD (Harding and Thom, 2001; Roy et al., 2020). In addition, abnormal neuronal stratification and microgliosis were also observed in the 

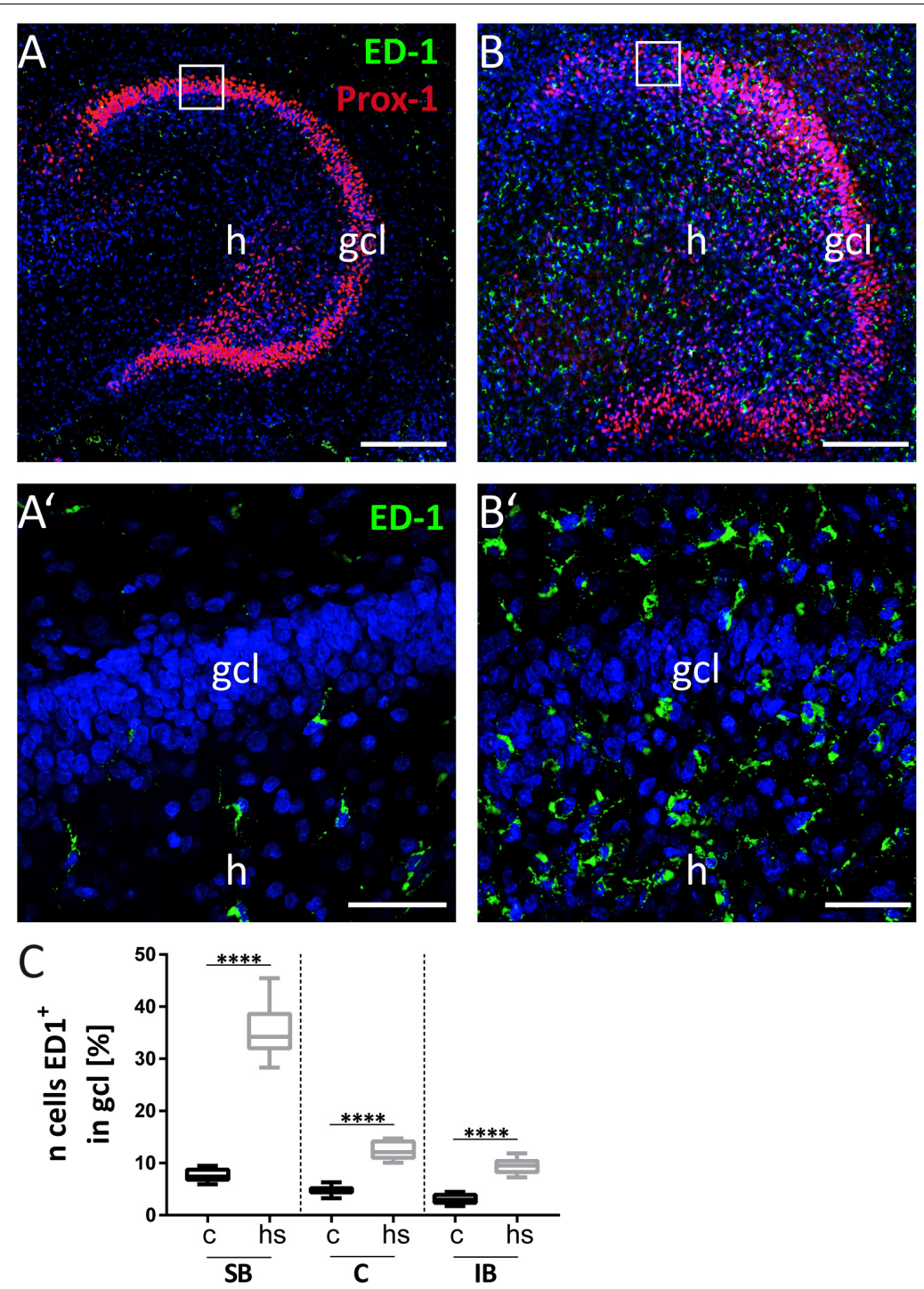

FIGURE 8 | Increased microgliosis in dentate granule cell layer (gcl). (A) Prox-1 immunostaining to label granule cells (red) in combination with anti-CD68 immunostaining (ED-1; green) to label microglia shows weak immunopositive signals for CD68 protein in control (boxed area of the gcl in $\mathbf{A}$, enlarged in $\mathbf{A}^{\prime}$ ). (B') After heat-shock, a strong immunopositive signal for the microglia marker ED-1 (green) can be seen. Enlargement of area is indicated by white square in (B). (C) Quantification of microglia cell numbers in gcl after heat-shock shows a significant increase, even more prominent when compared to the microglia increase in the mol (also compared to Figure 7C). Boxplots are shown with median, $25 \%$ and $75 \%$ quartile, minimum, and maximum. $n=27$. Asterisks indicate significance when $p<0.05$. gcl, granule cell layer; h, hilus. Scale bar (A,B): $200 \mu \mathrm{m}$; (A',B'): $50 \mu \mathrm{m}$.

hippocampus of seizure-free individuals, suggesting that GCD cannot be considered to be pathognomonic for TLE (Roy et al., 2020), much in contrast to earlier studies which had judged GCD to be a specific histopathological feature of TLE (Lurton et al., 1997; Koyama et al., 2012; Thom, 2014). Febrile seizures and ectopic granule cell positioning were hyperthermia-induced in rats in vivo (Koyama et al., 2012). To analyze the mechanisms that might underly aberrant granule cell migration in this model, organotypic slice cultures were prepared from animals subjected to hyperthermia, and the authors found that aberrant granule cell migration was caused by excitatory GABAergic signaling in dentate granule cells (Koyama et al., 2012). Reeler mutant mice which display severe cortical migration defects including dentate GCD do not show spontaneous seizure activity, though precisely timed activation of hippocampal neurons is affected in reeler (Kowalski et al., 2010). On the other side, autosomal dominant mutations in the human Reelin gene were identified that are causally linked to epileptic seizures (Dazzo et al., 2015). In this context, it is also interesting to note that in human patients with complex febrile seizures in early childhood, TLE and ammonshorn sclerosis were reported to be associated with an increased number of CR cells in the hippocampus formation (Blumcke et al., 1999). Certainly, further studies are required to characterize the cascade of events that lead to dispersion of granule cells after heat-shock. While in the extracellular matrix altered availability of signaling molecules and their proteolytic 

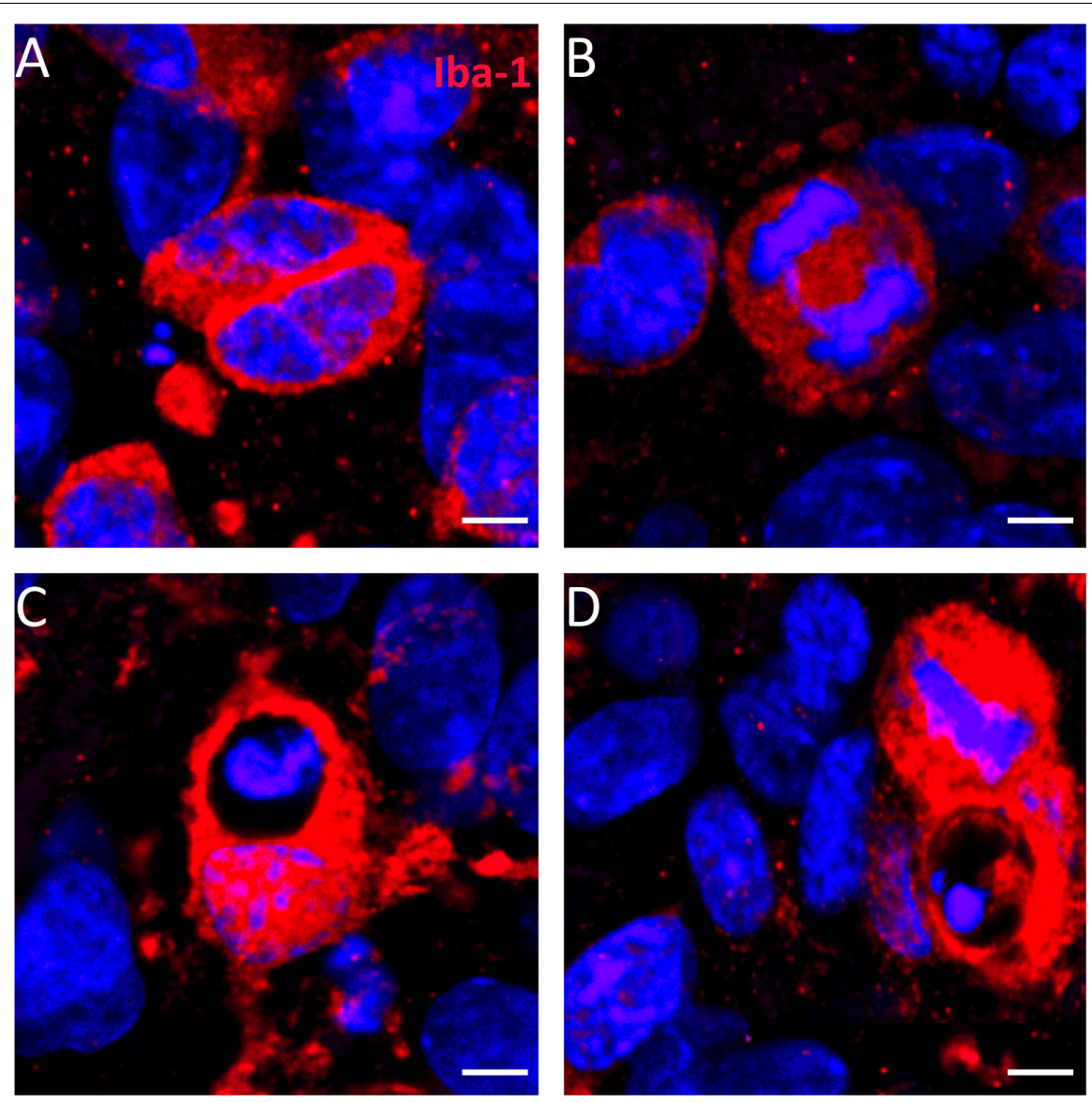

FIGURE 9 | Mitosis contributes to increased number of microglia in the molecular cell layer. When combining lba-1 staining (red) with DAPI nuclear staining (blue), we found diverse cell division stage of microglia in hippocampal slice cultures after heat-shock (A,B) but not in control slices (not shown). (C,D) Numerous microglia that phagocytize cell debris can be seen after heat-shock in hippocampal slice cultures. Scale bar: $10 \mu \mathrm{m}$.

cleavage may be involved, changes of the dynamics of cytoskeletal elements within the cell, such as actin filaments and microtubules, are a prerequisite for active displacement of neurons, including Reelin-controlled neuronal migration (Chai et al., 2009; Meseke et al., 2013; Forster, 2014).

\section{Heat-Shock Induces Massive Microgliosis in Hippocampal Slice Cultures}

Microglia cells, descendants of the monocyte-macrophage lineage, are involved in the detection of cerebral dysfunctions, infections or mechanical injuries and actively migrate to pathological lesion (Sieger et al., 2012). Microglial cells are also involved in the phagocytosis of cells, excreted cell components, and misfolded proteins (Walter and Neumann, 2009; Kettenmann et al., 2011). The activation of microglia is a characteristic feature of inflammatory conditions (Vezzani and Ruegg, 2011). In addition, glial cells also participate in epilepsyrelated events (Boer et al., 2006; Ravizza et al., 2006). There is recent evidence that active microglial brain surveillance prevents neuronal network hyperexcitability, while sustained reduction of microglial dynamics induces spontaneous seizures (Merlini et al., 2021). In this context, microglia may influence the heat-shockinduced tissue alterations described in the present hippocampal in vitro model. The increased activation of microglia is one of the main components under pathological conditions, for instance, reflecting inflammatory changes in nerve tissue (Vezzani and Ruegg, 2011). Ammonshorn sclerosis, i.e., degeneration of hippocampal neurons, is often associated with TLE (Blumcke et al., 2002) and accompanied by an increasing activation of microglial cells. Microglia may act inflammatory cytotoxic, but also beneficial neuroprotective. Thus, immunosuppressive effects on the surrounding tissue and cells were described (Colton, 2009; Kigerl et al., 2009; Czeh et al., 2011; Kettenmann et al., 2011; Tang and Le, 2016), and the pathological course of damaged tissue might be influenced in a positive way by invasion of microglia.

In our heat-shock model, we observed that the heat-shockinduced tissue damage was followed by a massive increase in the number of microglial cells in the dg, particularly in the gcl. Our findings suggest that subregion- and cell layer-specific differences exist in the microglial response to heat-shock (see Figures 7, 8), likely reflecting local differences in inflammatory reactions. Accordingly, the gcl, where a large number of 
neurons were damaged by the heat-shock, was infiltrated by microglia cells. Microgliosis was at least in part caused by an increased mitotic cell division of microglia, as witnessed by microglia mitotic figures in the slice cultures after heat-shock (see Figures 9A,B). In addition, infiltration of migrating microglia contributed to microgliosis. However, in other studies, microglia activation was also observed without cell loss, apparently induced by seizures alone, and without immediate synthesis of inflammatory mediators (Vezzani et al., 2000; Ravizza et al., 2008; Dube et al., 2010; Maroso et al., 2011; Devinsky et al., 2013). To answer the question to what extent the heat-shock itself or liberation of inflammatory mediators contributes to the activation of microglia, further experimental studies are required. If phagocytosis of dead cells reduces the damage of the hippocampus (see Figures 9C,D), their elimination would be an essential component in the remission of pathological changes after heat-shock. Further studies are required to assess a positive curative effect or, in the case of incomplete phagocytosis, a detrimental effect on the pathogenesis. Thus, potentially microglia activation could represent a measurable parameter of the immune system attempting to reduce neuronal cell loss. For instance, it cannot be conclusively determined whether the increase in the number of activated phagocytic microglial cells [rounded phagocytic type (RPT)] indicates a pro- or an anti-inflammatory potential or a pro- or an anti-convulsive effect, respectively. Of course, our results cannot be directly transferred to the interpretation of epilepsy-affected hippocampi, because the slice cultures were derived from healthy rats not suffering from epilepsy. They might, however, be useful as a model to interpret the role of an inflammatory state in the brain, possibly favoring the development of epilepsy. In this context, it should be noted that Roy et al. (2020), who recently reported on GCD as a non-specific finding in pediatric patients, did not observe a microglia reaction in the analyzed hippocampal tissue with no history of seizures. This finding, together with our observation of microgliosis after heat-shock, underpins the importance of microgliosis as an important parameter to distinguish pathological from nonspecific granule dispersion.

Another question that remains to be addressed is whether the transient temperature increase induces epileptic activity in the hippocampal slices. Studies on hyperthermia-induced seizures in immature rats were performed earlier (Holtzman et al., 1981; Tancredi et al., 1992; Tsai and Leung, 2006), with electrocortical paroxysmal discharges reported to be similar to those in infants (Holtzman et al., 1981). Results with an altered excitability in slice cultures suggest that anti-inflammatory and protective effects of microglia may influence the outcome of the pathology (Colton, 2009; Kigerl et al., 2009; Czeh et al., 2011; Kettenmann et al., 2011; Tang and Le, 2016). In this regard, it could be interesting to explore if manipulation of the

\section{REFERENCES}

Abou-Khalil, B., Andermann, E., Andermann, F., Olivier, A., and Quesney, L. F. (1993). Temporal lobe epilepsy after prolonged febrile convulsions: excellent heat-shock-induced microglial response may promote neuronal survival and to reduce damage of surviving neurons. However, microglial cells could also maintain the inflammatory state in the brain or activate other inflammatory pathways, confirming the concept of an induced inflammation and enhancement of pathology by glial cells (Stoll and Jander, 1999; Vezzani et al., 2011; Galic et al., 2012; Devinsky et al., 2013). Thus, microglial inactivation could contribute to a possible improvement of the cerebral state, by reducing the amount of neurotoxic factors, even if the underlying cause of the disease may not be cured (Nelson et al., 2002). Overall, currently, few studies on effects of heat-shock on neural tissue in vitro exist. Here we provide evidence that microglia cells play a remarkable role in the heatshock response in hippocampal slice cultures. The relationship between heat-shock, induced GCD and microglia activation is largely unexplored. Further experimental studies on the interplay between neuropathology and the microglia response may help to progress existing therapeutic options in the pathogenesis of febrile seizures and other neurological diseases.

\section{DATA AVAILABILITY STATEMENT}

The original contributions presented in the study are included in the article/supplementary material. Further inquiries can be directed to the corresponding author/s.

\section{ETHICS STATEMENT}

The animal study was reviewed and approved by Landesamt für Natur, Umwelt und Verbraucherschutz Nordrhein-Westfalen.

\section{AUTHOR CONTRIBUTIONS}

JW and MM performed experimental work and statistical analysis of data, and contributed to data interpretation and manuscript writing. SR performed experimental work on Prox-1 in combination with PI staining. EF developed the concept of the study and was involved in data interpretation and manuscript writing. All authors contributed to the article and approved the submitted version.

\section{ACKNOWLEDGMENTS}

We thank Katja Rumpf, Corinna Wojczak, and Jeannette Willms for their excellent technical assistance. We acknowledge support by the Open Access Publication Funds of the Ruhr-Universität Bochum.

outcome after surgical treatment. Epilepsia 34, 878-883. doi: 10.1111/j.15281157.1993.tb02105.x

Altman, J., and Das, G. D. (1965). Autoradiographic and histological evidence of postnatal hippocampal neurogenesis 
in rats. J. Comp. Neurol. 124, 319-335. doi: 10.1002/cne.9012 40303

Antonucci, F., Bozzi, Y., and Caleo, M. (2009). Intrahippocampal infusion of botulinum neurotoxin $\mathrm{E}$ (BoNT/E) reduces spontaneous recurrent seizures in a mouse model of mesial temporal lobe epilepsy. Epilepsia 50, 963-966. doi: 10.1111/j.1528-1167.2008.01983.x

Bender, R. A., Dube, C., and Baram, T. Z. (2004). Febrile seizures and mechanisms of epileptogenesis: insights from an animal model. Adv. Exp. Med. Biol. 548, 213-225. doi: 10.1007/978-1-4757-6376-8_15

Blumcke, I., Beck, H., Suter, B., Hoffmann, D., Fodisch, H. J., Wolf, H. K., et al. (1999). An increase of hippocampal calretinin-immunoreactive neurons correlates with early febrile seizures in temporal lobe epilepsy. Acta Neuropathol. 97, 31-39. doi: 10.1007/s004010050952

Blumcke, I., Kistner, I., Clusmann, H., Schramm, J., Becker, A. J., Elger, C. E., et al. (2009). Towards a clinico-pathological classification of granule cell dispersion in human mesial temporal lobe epilepsies. Acta Neuropathol. 117, 535-544. doi: 10.1007/s00401-009-0512-5

Blumcke, I., Thom, M., and Wiestler, O. D. (2002). Ammon's horn sclerosis: a maldevelopmental disorder associated with temporal lobe epilepsy. Brain Pathol. 12, 199-211.

Boer, K., Spliet, W. G., van Rijen, P. C., Redeker, S., Troost, D., and Aronica, E. (2006). Evidence of activated microglia in focal cortical dysplasia. J. Neuroimmunol. 173, 188-195. doi: 10.1016/j.jneuroim.2006.01.002

Bozzi, Y., Casarosa, S., and Caleo, M. (2012). Epilepsy as a neurodevelopmental disorder. Front. Psychiatry 3:19. doi: 10.3389/fpsyt.2012. 00019

Cameron, M. C., Zhan, R. Z., and Nadler, J. V. (2011). Morphologic Integration of Hilar Ectopic Granule Cells into Dentate Gyrus Circuitry in the Pilocarpine Model of Temporal Lobe Epilepsy. J. Comparat. Neurol. 519, 2175-2192. doi: $10.1002 /$ cne. 22623

Cendes, F., Andermann, F., Dubeau, F., Gloor, P., Evans, A., Jones-Gotman, M., et al. (1993). Early childhood prolonged febrile convulsions, atrophy and sclerosis of mesial structures, and temporal lobe epilepsy: an MRI volumetric study. Neurology 43, 1083-1087. doi: 10.1212/wnl.43.6.1083

Chai, X., Forster, E., Zhao, S., Bock, H. H., and Frotscher, M. (2009). Reelin acts as a stop signal for radially migrating neurons by inducing phosphorylation of $\mathrm{n}$-cofilin at the leading edge. Commun. Integr. Biol. 2, 375-377. doi: 10.4161/ cib.2.4.8614

Choi, J., and Koh, S. (2008). Role of brain inflammation in epileptogenesis. Yonsei Med. J. 49, 1-18. doi: 10.3349/ymj.2008.49.1.1

Colton, C. A. (2009). Heterogeneity of microglial activation in the innate immune response in the brain. J. Neuroimmune Pharmacol. 4, 399-418. doi: 10.1007/ s11481-009-9164-4

Curia, G., Longo, D., Biagini, G., Jones, R. S., and Avoli, M. (2008). The pilocarpine model of temporal lobe epilepsy. J. Neurosci. Methods 172, 143-157. doi: 10. 1016/j.jneumeth.2008.04.019

Czeh, M., Gressens, P., and Kaindl, A. M. (2011). The yin and yang of microglia. Dev. Neurosci. 33, 199-209. doi: 10.1159/000328989

D'Arcangelo, G., Miao, G. G., Chen, S. C., Soares, H. D., Morgan, J. I., and Curran, T. (1995). A protein related to extracellular matrix proteins deleted in the mouse mutant reeler. Nature 374, 719-723. doi: 10.1038/374719a0

D’Arcangelo, G., Nakajima, K., Miyata, T., Ogawa, M., Mikoshiba, K., and Curran, T. (1997). Reelin is a secreted glycoprotein recognized by the CR-50 monoclonal antibody. J. Neurosci. 17, 23-31.

Dashtipour, K., Tran, P. H., Okazaki, M. M., Nadler, J. V., and Ribak, C. E. (2001). Ultrastructural features and synaptic connections of hilar ectopic granule cells in the rat dentate gyrus are different from those of granule cells in the granule cell layer. Brain Res. 890, 261-271. doi: 10.1016/S0006-8993(00)03119-X

Dazzo, E., Fanciulli, M., Serioli, E., Minervini, G., Pulitano, P., Binelli, S., et al. (2015). Heterozygous reelin mutations cause autosomal-dominant lateral temporal epilepsy. Am. J. Hum. Genet. 96, 992-1000. doi: 10.1016/j.ajhg.2015. 04.020

Del Rio, J. A., Heimrich, B., Super, H., Borrell, V., Frotscher, M., and Soriano, E. (1996). Differential survival of Cajal-Retzius cells in organotypic cultures of hippocampus and neocortex. J. Neurosci. 16, 6896-6907.

del Rio, J. A., and Soriano, E. (2010). Regenerating cortical connections in a dish: the entorhino-hippocampal organotypic slice co-culture as tool for pharmacological screening of molecules promoting axon regeneration. Nat. Protocols 5, 217-226. doi: 10.1038/nprot.2009.202

Devinsky, O., Vezzani, A., Najjar, S., De Lanerolle, N. C., and Rogawski, M. A. (2013). Glia and epilepsy: excitability and inflammation. Trends Neurosci. 36, 174-184. doi: 10.1016/j.tins.2012.11.008

Dube, C. M., Brewster, A. L., and Baram, T. Z. (2009). Febrile seizures: mechanisms and relationship to epilepsy. Brain Dev. 31, 366-371. doi: 10.1016/j.braindev. 2008.11.010

Dube, C. M., Ravizza, T., Hamamura, M., Zha, Q., Keebaugh, A., Fok, K., et al. (2010). Epileptogenesis provoked by prolonged experimental febrile seizures: mechanisms and biomarkers. J. Neurosci. 30, 7484-7494. doi: 10.1523/ JNEUROSCI.0551-10.2010

Duveau, V., Madhusudan, A., Caleo, M., Knuesel, I., and Fritschy, J. M. (2011). Impaired reelin processing and secretion by Cajal-Retzius cells contributes to granule cell dispersion in a mouse model of temporal lobe epilepsy. Hippocampus 21, 935-944. doi: 10.1002/hipo.20793

Eyo, U. B., and Dailey, M. E. (2013). Microglia: key elements in neural development, plasticity, and pathology. J. Neuroimmune Pharmacol. 8, 494509. doi: 10.1007/s11481-013-9434-z

Folsom, T. D., and Fatemi, S. H. (2013). The involvement of Reelin in neurodevelopmental disorders. Neuropharmacology 68, 122-135. doi: 10.1016/ j.neuropharm.2012.08.015

Forster, E. (2014). Reelin, neuronal polarity and process orientation of cortical neurons. Neuroscience 269, 102-111. doi: 10.1016/j.neuroscience.2014.03.004

Forster, E., Jossin, Y., Zhao, S., Chai, X., Frotscher, M., and Goffinet, A. M. (2006a). Recent progress in understanding the role of Reelin in radial neuronal migration, with specific emphasis on the dentate gyrus. Eur. J. Neurosci. 23, 901-909. doi: 10.1111/j.1460-9568.2006.04612.x

Forster, E., Otten, U., and Frotscher, M. (1993). Developmental neurotrophin expression in slice cultures of rat hippocampus. Neurosci. Lett. 155, 216-219. doi: 10.1016/0304-3940(93)90711-s

Forster, E., Zhao, S., and Frotscher, M. (2006b). Laminating the hippocampus. Nat. Rev. Neurosci. 7, 259-267. doi: 10.1038/nrn1882

French, J. A., Williamson, P. D., Thadani, V. M., Darcey, T. M., Mattson, R. H., Spencer, S. S., et al. (1993). Characteristics of medial temporal lobe epilepsy: I. Results of history and physical examination. Ann. Neurol. 34, 774-780. doi: 10.1002/ana.410340604

Frotscher, M. (1998). Cajal-Retzius cells, Reelin, and the formation of layers. Curr. Opin. Neurobiol. 8, 570-575. doi: 10.1016/s0959-4388(98)80082-2

Galic, M. A., Riazi, K., and Pittman, Q. J. (2012). Cytokines and brain excitability. Front. Neuroendocrinol. 33:116-125. doi: 10.1016/j.yfrne.2011.12.002

Gong, C., Wang, T. W., Huang, H. S., and Parent, J. M. (2007). Reelin regulates neuronal progenitor migration in intact and epileptic hippocampus. J. Neurosci. 27, 1803-1811. doi: 10.1523/JNEUROSCI.3111-06.2007

Haas, C. A., Dudeck, O., Kirsch, M., Huszka, C., Kann, G., Pollak, S., et al. (2002). Role for reelin in the development of granule cell dispersion in temporal lobe epilepsy. J. Neurosci. 22, 5797-5802.

Haas, C. A., and Frotscher, M. (2010). Reelin deficiency causes granule cell dispersion in epilepsy. Exp. Brain Res. 200, 141-149. doi: 10.1007/s00221-0091948-5

Hack, I., Hellwig, S., Junghans, D., Brunne, B., Bock, H. H., Zhao, S., et al. (2007). Divergent roles of ApoER2 and Vldlr in the migration of cortical neurons. Development 134, 3883-3891. doi: 10.1242/dev.005447

Hanisch, U. K., and Kettenmann, H. (2007). Microglia: active sensor and versatile effector cells in the normal and pathologic brain. Nat. Neurosci. 10, 1387-1394. doi: 10.1038/nn1997

Harding, B., and Thom, M. (2001). Bilateral hippocampal granule cell dispersion: autopsy study of 3 infants. Neuropathol. Appl. Neurobiol. 27, 245-251. doi: 10.1046/j.0305-1846.2001.00325.x

Hayashi, K., Kubo, K., Kitazawa, A., and Nakajima, K. (2015). Cellular dynamics of neuronal migration in the hippocampus. Front. Neurosci. 9:135. doi: 10.3389/ fnins.2015.00135

Heinrich, C., Nitta, N., Flubacher, A., Muller, M., Fahrner, A., Kirsch, M., et al. (2006). Reelin deficiency and displacement of mature neurons, but not neurogenesis, underlie the formation of granule cell dispersion in the epileptic hippocampus. J. Neurosci. 26, 4701-4713. doi: 10.1523/JNEUROSCI.5516-05. 2006 
Holtzman, D., Obana, K., and Olson, J. (1981). Hyperthermia-induced seizures in the rat pup: a model for febrile convulsions in children. Science 213, 1034-1036. doi: $10.1126 /$ science. 7268407

Houser, C. R. (1990). Granule cell dispersion in the dentate gyrus of humans with temporal lobe epilepsy. Brain Res. 535, 195-204. doi: 10.1016/0006-8993(90) 91601-c

Houser, C. R. (1999). Neuronal loss and synaptic reorganization in temporal lobe epilepsy. Adv. Neurol. 79, 743-761.

Kettenmann, H., Hanisch, U. K., Noda, M., and Verkhratsky, A. (2011). Physiology of microglia. Physiol. Rev. 91, 461-553. doi: 10.1152/physrev.00011.2010

Kigerl, K. A., Gensel, J. C., Ankeny, D. P., Alexander, J. K., Donnelly, D. J., and Popovich, P. G. (2009). Identification of two distinct macrophage subsets with divergent effects causing either neurotoxicity or regeneration in the injured mouse spinal cord. J. Neurosci. 29, 13435-13444. doi: 10.1523/JNEUROSCI. 3257-09.2009

Kohno, S., Kohno, T., Nakano, Y., Suzuki, K., Ishii, M., Tagami, H., et al. (2009). Mechanism and significance of specific proteolytic cleavage of Reelin. Biochem. Biophys. Res. Commun. 380, 93-97. doi: 10.1016/j.bbrc.2009.01.039

Kowalski, J., Geuting, M., Paul, S., Dieni, S., Laurens, J., Zhao, S., et al. (2010). Proper layering is important for precisely timed activation of hippocampal mossy cells. Cereb Cortex 20, 2043-2054. doi: 10.1093/cercor/bhp267

Koyama, R. (2013). The use of organotypic slice cultures for the study of epileptogenesis. Neuropathology 33, 475-479. doi: 10.1111/neup.12019

Koyama, R., Tao, K., Sasaki, T., Ichikawa, J., Miyamoto, D., Muramatsu, R., et al. (2012). GABAergic excitation after febrile seizures induces ectopic granule cells and adult epilepsy. Nat. Med. 18, 1271-1278. doi: 10.1038/nm.2850

Lambert de Rouvroit, C., de Bergeyck, V., Cortvrindt, C., Bar, I., Eeckhout, Y., et al. (1999). Reelin, the extracellular matrix protein deficient in reeler mutant mice, is processed by a metalloproteinase. Exp. Neurol. 156, 214-217. doi: 10.1006/ exnr.1998.7007

Lurton, D., Sundstrom, L., Brana, C., Bloch, B., and Rougier, A. (1997). Possible mechanisms inducing granule cell dispersion in humans with temporal lobe epilepsy. Epilepsy. Res. 26, 351-361. doi: 10.1016/s0920-1211(96)01002-9

Maroso, M., Balosso, S., Ravizza, T., Iori, V., Wright, C. I., French, J., et al. (2011). Interleukin-1beta biosynthesis inhibition reduces acute seizures and drug resistant chronic epileptic activity in mice. Neurotherapeutics 8, 304-315. doi: 10.1007/s13311-011-0039-z

Merlini, M., Rafalski, V. A., Ma, K., Kim, K. Y., Bushong, E. A., Rios Coronado, P. E., et al. (2021). Microglial Gi-dependent dynamics regulate brain network hyperexcitability. Nat. Neurosci. 24, 19-23. doi: 10.1038/s41593-020-00756-7

Meseke, M., Cavus, E., and Forster, E. (2013). Reelin promotes microtubule dynamics in processes of developing neurons. Histochem. Cell Biol. 139, $283-$ 297. doi: 10.1007/s00418-012-1025-1

Muller, M. C., Osswald, M., Tinnes, S., Haussler, U., Jacobi, A., Forster, E., et al. (2009). Exogenous reelin prevents granule cell dispersion in experimental epilepsy. Exp. Neurol. 216, 390-397. doi: 10.1016/j.expneurol.2008.12.029

Nelson, P. T., Soma, L. A., and Lavi, E. (2002). Microglia in diseases of the central nervous system. Ann. Med. 34, 491-500. doi: 10.1080/078538902321117698

Orcinha, C., Munzner, G., Gerlach, J., Kilias, A., Follo, M., Egert, U., et al. (2016). Seizure-Induced Motility of Differentiated Dentate Granule Cells Is Prevented by the Central Reelin Fragment. Front. Cell. Neurosci. 10:00183. doi: 10.3389/ fncel.2016.00183

Pahle, J., Muhia, M., Wagener, R. J., Tippmann, A., Bock, H. H., Graw, J., et al. (2020). Selective Inactivation of Reelin in Inhibitory Interneurons Leads to Subtle Changes in the Dentate Gyrus But Leaves Cortical Layering and Behavior Unaffected. Cereb. Cortex 30, 1688-1707. doi: 10.1093/cercor/bhz196

Ravizza, T., Boer, K., Redeker, S., Spliet, W. G., van Rijen, P. C., Troost, D., et al. (2006). The IL-1beta system in epilepsy-associated malformations of cortical development. Neurobiol. Dis. 24, 128-143. doi: 10.1016/j.nbd.2006.06.003

Ravizza, T., Gagliardi, B., Noe, F., Boer, K., Aronica, E., and Vezzani, A. (2008). Innate and adaptive immunity during epileptogenesis and spontaneous seizures: evidence from experimental models and human temporal lobe epilepsy. Neurobiol. Dis. 29, 142-160. doi: 10.1016/j.nbd.2007.08.012

Rice, D. S., and Curran, T. (2001). Role of the reelin signaling pathway in central nervous system development. Annu. Rev. Neurosci. 24, 1005-1039. doi: 10. 1146/annurev.neuro.24.1.1005

Rocca, W. A., Sharbrough, F. W., Hauser, W. A., Annegers, J. F., and Schoenberg, B. S. (1987). Risk factors for complex partial seizures: a population-based case-control study. Ann. Neurol. 21, 22-31. doi: 10.1002/ana.410210106
Roy, A., Millen, K. J., and Kapur, R. P. (2020). Hippocampal granule cell dispersion: a non-specific finding in pediatric patients with no history of seizures. Acta Neuropathol. Commun. 8:54. doi: 10.1186/s40478-02000928-3

Sieger, D., Moritz, C., Ziegenhals, T., Prykhozhij, S., and Peri, F. (2012). Longrange Ca2+ waves transmit brain-damage signals to microglia. Dev. Cell 22, 1138-1148. doi: 10.1016/j.devcel.2012.04.012

Stanfield, B. B., and Cowan, W. M. (1979). Development of the Hippocampus and Dentate Gyrus in Normal and Reeler Mice. J. Comparat. Neurol. 185, 423-459. doi: 10.1002/cne.901850303

Stegen, M., Young, C. C., Haas, C. A., Zentner, J., and Wolfart, J. (2009). Increased leak conductance in dentate gyrus granule cells of temporal lobe epilepsy patients with Ammon's horn sclerosis. Epilepsia 50, 646-653. doi: 10.1111/j. 1528-1167.2009.02025.x

Stoll, G., and Jander, S. (1999). The role of microglia and macrophages in the pathophysiology of the CNS. Prog. Neurobiol. 58, 233-247. doi: 10.1016/s03010082(98)00083-5

Sugiyama, T., Osumi, N., and Katsuyama, Y. (2013). The Germinal Matrices in the Developing Dentate Gyrus are Composed of Neuronal Progenitors at Distinct Differentiation Stages. Dev. Dynam. 242, 1442-1453. doi: 10.1002/dvdy. 24035

Tancredi, V., D’Arcangelo, G., Zona, C., Siniscalchi, A., and Avoli, M. (1992). Induction of epileptiform activity by temperature elevation in hippocampal slices from young rats: an in vitro model for febrile seizures? Epilepsia 33, 228-234. doi: 10.1111/j.1528-1157.1992.tb02311.x

Tang, Y., and Le, W. (2016). Differential Roles of M1 and M2 Microglia in Neurodegenerative Diseases. Mol. Neurobiol. 53, 1181-1194. doi: 10.1007/ s12035-014-9070-5

Thom, M. (2014). Review: Hippocampal sclerosis in epilepsy: a neuropathology review. Neuropathol. Appl. Neurobiol. 40, 520-543. doi: 10.1111/nan. 12150

Tinnes, S., Ringwald, J., and Haas, C. A. (2013). TIMP-1 inhibits the proteolytic processing of Reelin in experimental epilepsy. FASEB J. 27, 2542-2552. doi: 10.1096/fj.12-224899

Tissir, F., and Goffinet, A. M. (2003). Reelin and brain development. Nat. Rev. Neurosci. 4, 496-505. doi: 10.1038/nrn1113

Tsai, M. L., and Leung, L. S. (2006). Decrease of hippocampal GABA B receptormediated inhibition after hyperthermia-induced seizures in immature rats. Epilepsia 47, 277-287. doi: 10.1111/j.1528-1167.2006.00419.x

Vezzani, A., French, J., Bartfai, T., and Baram, T. Z. (2011). The role of inflammation in epilepsy. Nat. Rev. Neurol. 7, 31-40. doi: 10.1038/nrneurol. 2010.178

Vezzani, A., and Granata, T. (2005). Brain inflammation in epilepsy: experimental and clinical evidence. Epilepsia 46, 1724-1743. doi: 10.1111/j.1528-1167.2005. 00298.x

Vezzani, A., Moneta, D., Conti, M., Richichi, C., Ravizza, T., De Luigi, A., et al. (2000). Powerful anticonvulsant action of IL-1 receptor antagonist on intracerebral injection and astrocytic overexpression in mice. Proc. Natl. Acad. Sci. U S A 97, 11534-11539. doi: 10.1073/pnas.190206797

Vezzani, A., and Ruegg, S. (2011). The pivotal role of immunity and inflammatory processes in epilepsy is increasingly recognized: introduction. Epilepsia 52(Suppl. 3), 1-4. doi: 10.1111/j.1528-1167.2011.03028.x

Walter, L., and Neumann, H. (2009). Role of microglia in neuronal degeneration and regeneration. Semin. Immunopathol. 31, 513-525. doi: 10.1007/s00281009-0180-5

Zhao, S., Chai, X., Forster, E., and Frotscher, M. (2004). Reelin is a positional signal for the lamination of dentate granule cells. Development 131, 5117-5125. doi: $10.1242 /$ dev.01387

Conflict of Interest: The authors declare that the research was conducted in the absence of any commercial or financial relationships that could be construed as a potential conflict of interest.

Copyright (C) 2021 Weninger, Meseke, Rana and Förster. This is an open-access article distributed under the terms of the Creative Commons Attribution License (CC BY). The use, distribution or reproduction in other forums is permitted, provided the original author(s) and the copyright owner(s) are credited and that the original publication in this journal is cited, in accordance with accepted academic practice. No use, distribution or reproduction is permitted which does not comply with these terms. 